\title{
Wavy-ply sandwich with composite skins and crushable core for ductility and energy absorption
}

\author{
Soraia Pimenta ${ }^{\mathrm{a}, *}$, Paul Robinson ${ }^{\mathrm{b}}$ \\ ${ }^{a}$ The Composites Centre, Department of Mechanical Engineering, South Kensington Campus, Imperial \\ College London, SW7 2AZ, United Kingdom \\ ${ }^{b}$ The Composites Centre, Department of Aeronautics, South Kensington Campus, Imperial College London, \\ SWr 2AZ, United Kingdom
}

\begin{abstract}
Conventional composite materials offer high specific stiffness and strength, but suffer from low failure strains and failure without warning. This work proposes a new design for sandwich structures with symmetrically-wavy composite skins and a crushable foam core, aiming to achieve large strains (due to unfolding of the skins) and energy absorption (due to crushing of the foam core) under tensile loading. The structure is designed by a combination of analytical modelling and finite element simulations, and the concept is demonstrated experimentally. When loaded under quasi-static tension, wavy-ply sandwich specimens with carbon-epoxy skins and optimised geometry exhibited an average failure strain of $8.6 \%$, a specific energy dissipated of $9.4 \mathrm{~kJ} / \mathrm{kg}$, and ultimate strength of $1570 \mathrm{MPa}$. The scope for further developing the wavy-ply sandwich concept and potential applications requiring large deformations and energy absorption are discussed.
\end{abstract}

Keywords: Sandwich structures, Non-linear behaviour, Finite Element Analysis, Mechanical testing, Large deformations

\section{Introduction}

Fibre-Reinforced Polymers (FRPs) are remarkably stiff, strong and light materials, which makes them advantageous for lightweight structural applications. However, FRPs present a restricted ability to deform and withstand damage before catastrophic failure, which limits their applicability in damage tolerant components. This paper proposes a wavy-ply sandwich structure to generate significant ductility and energy absorption in FRPs.

Increasing the ductility of composites requires engineering extra deformation mechanisms, since most technical fibres (e.g. carbon and glass) have low extensions at failure. One possibil-

\footnotetext{
${ }^{*}$ Corresponding author.

Email address: soraia.pimenta@imperial.ac.uk (Soraia Pimenta)
}

Pimenta S, Robinson P (2014). Wavy-ply sandwich with composite skins and crushable core for ductility and energy absorption. Composites Structures 116, 364-376. DOI:10.1016/j.compstruct.2014.05.020 
ity is to use fibre waviness to provide excess length and allow for further extensions due to fibre re-orientation during loading [1-3]. This requires tailoring the response of the matrix, which should be sufficiently stiff to provide initial resistance to fibre rotation, but flexible enough to accommodate large deformations due to fibre unfolding at higher loads. This concept has been explored by using waviness at the fibre level [1, 2] or corrugated plies [3].

Increasing the energy absorption of composites requires introducing mechanisms to spread the damage and avoid localised failure. A typical solution is to use sandwich structures, where the composite skins provide stiffness and strength, and a light crushable core dissipates damage and energy. Sandwich structures used under crushing $[4,5]$ or bending $[6,7]$ show greater specific energy absorptions than the monolithic counterparts.

These strategies can be combined into sandwich materials with wavy skins. Several authors [8-11] analysed asymmetric sandwich structures composed by one straight skin, one wavy skin with periodic profile, and a matching machined foam core. Under tension, the straight skin would initially carry the load until first fracture within one of the periodic cells; the wavy skin would then unfold and stretch locally, transferring the load back to the remaining straight segments at stitched points. This process would be repeated until the straight skin was fractured in all periodic cells, and the wavy skin was fully stretched.

Such asymmetric sandwich structures [8-11] achieved larger failure strains and specific work of fracture than the corresponding monolithic materials. However, most energy was dissipated unstably, with significant load drops following each fracture event of the straight skin. Moreover, the foam core was used simply to define the wavy profile, and its potential to absorb energy was not explored.

These drawbacks suggest that the potential of wavy-ply sandwich structures for large deformations and energy absorption has not been fully exploited yet. This work proposes a sandwich structure with symmetric wavy skins and a crushable core, aiming to combine (i) large deformations (through fibre re-orientation), (ii) energy absorption (through crushing of the core), and (iii) a stable non-linear tensile response (with no significant load drops).

The new wavy-ply sandwich concept [12] is illustrated in Figure 1 and further described in Section 2. The sandwich structure is designed in Section 3, using a combination of analytical and Finite Element (FE) modelling. Section 4 describes the manufacturing and testing of wavy-ply sandwich specimens, and the results from the experimental characterisation are detailed in Section 5. The potential of the proposed concept is discussed in Section 6, and the main conclusions are summarised in Section 7.

\section{Concept and materials}

The wavy-ply sandwich concept [12] is designed for in-plane tensile loading (see Figure 1) and relies on the following three components: 


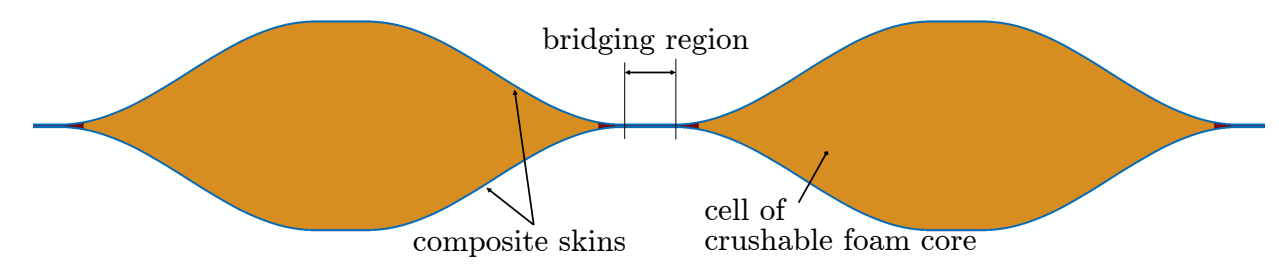

(a) Original configuration.

(b) Deformed configuration.

Figure 1: Wavy-ply sandwich concept.

- Wavy skins: the skins are the main load-carrying element. Their initial waviness will provide excess length during tensile loading, allowing for large remote extensions through unfolding. The skins will be manufactured with a Carbon-Fibre Reinforced-Polymer (CFRP) with toughened epoxy matrix (Hexcel M21/35\%/198/T800S [13-16]);

- Crushable core: while the core should provide initial stiffness to the system, it will allow the wavy skins to unfold with further loading and absorb energy through crushing. The crushable core cells will be machined from EVONIK ROHACELL RIMA foam (highperformance closed-cell PMI-based foams, specifically developed for minimal resin absorption) [17], and bonded in-situ during the cure of the CFRP skins;

- Bridging region: the bridging region (where the two skins are bonded together) will experience opening stresses due to the initial stiffness of the core, with large stress concentrations at the edges of the core cells. Fillets of resin (made from Hexcel M21 film [13]) will therefore be used to prevent delamination (see Figure 2).

Properties of the materials are provided in Tables 1 to 5 . The next section will define the remaining design variables of the concept (see Figure 2).

\section{Modelling and design}

\subsection{Analytical modelling and wave geometry design}

\subsubsection{Model development}

The strength and maximum extension of the wavy-ply sandwich structure under remote tension can be estimated through the analysis of the wavy skins (of thickness $t^{\mathrm{w}}$ ) under bending coupled with tension, neglecting the presence of the (by then failed) foam.

Consider the sinusoidal profile $y(x)$ represented in Figure 2 ; this is characterised by the half-length $L^{\mathrm{w}}$ and half-amplitude $A^{\mathrm{w}}$, so that the aspect ratio is $\alpha=A^{\mathrm{w}} / L^{\mathrm{w}}$ and: 


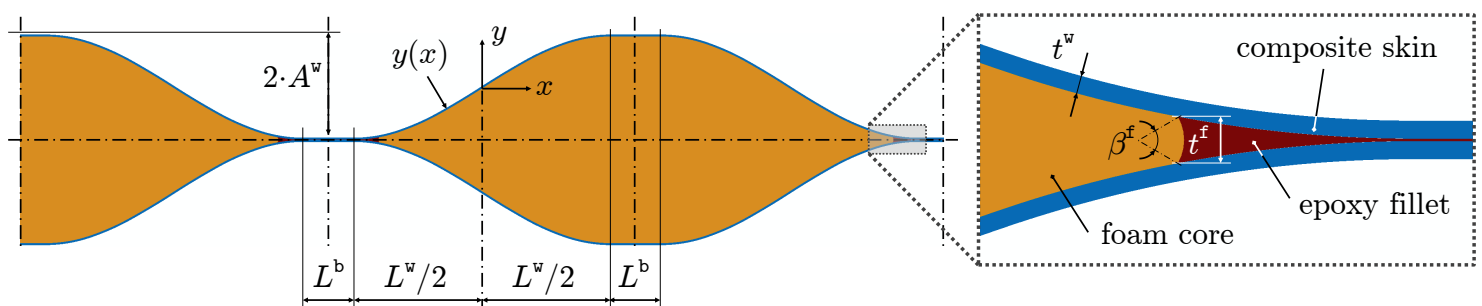

Figure 2: Geometry of the wavy-ply sandwich structure, highlighting the design variables to be defined through modelling: (i) geometry of the wavy profile, (ii) geometry of the bridging region, and (iii) density of the foam for the crushable core.

Table 1: Geometric and mass properties of the M21 matrix (superscript m) and M21/35\%/198/T800S CFRP plies (superscript p) [13].

\begin{tabular}{cccccc}
\hline$t^{\mathrm{m}}(\mathrm{mm})$ & $\rho^{\mathrm{m}}\left(\mathrm{g} / \mathrm{cm}^{3}\right)$ & $w^{\mathrm{m}}\left(\mathrm{g} / \mathrm{m}^{2}\right)$ & $t^{\mathrm{p}}(\mathrm{mm})$ & $\rho^{\mathrm{p}}\left(\mathrm{g} / \mathrm{cm}^{3}\right)$ & $w^{\mathrm{p}}\left(\mathrm{g} / \mathrm{m}^{2}\right)$ \\
\hline 0.027 & 1.28 & 35 & 0.193 & 1.58 & 305 \\
\hline
\end{tabular}

Table 2: Elastic properties of the M21 matrix (superscript m) and M21/35\%/198/T800S CFRP plies (superscript $\mathrm{p})$.

\begin{tabular}{lccccccc}
\hline $\begin{array}{c}E^{\mathrm{m}} \\
(\mathrm{GPa})\end{array}$ & $\begin{array}{c}\nu^{\mathrm{m}} \\
(-)\end{array}$ & $\begin{array}{c}E_{1}^{\mathrm{p}} \\
(\mathrm{GPa})\end{array}$ & $\begin{array}{c}E_{2}^{\mathrm{p}}=E_{3}^{\mathrm{p}} \\
(\mathrm{GPa})\end{array}$ & $\begin{array}{c}G_{12}^{\mathrm{p}}=G_{13}^{\mathrm{p}} \\
(\mathrm{GPa})\end{array}$ & $\begin{array}{c}G_{23}^{\mathrm{p}} \\
(\mathrm{GPa})\end{array}$ & $\begin{array}{c}\nu_{12}^{\mathrm{p}}=\nu_{13}^{\mathrm{p}} \\
(-)\end{array}$ & $\begin{array}{c}\nu_{23}^{\mathrm{p}} \\
(-)\end{array}$ \\
\hline $3.5[13]$ & $0.4^{(\dagger)}$ & $165[13,14]$ & $9.3[14]$ & $4.8[13]$ & $3.1^{(\star)}$ & $0.33[14]$ & $0.5^{(\dagger)}$ \\
\hline $\begin{array}{l}{ }^{(\star)} \text { Calculated assuming transverse isotropy. } \\
{ }^{\dagger} \text { Estimated value. }\end{array}$
\end{tabular}

Table 3: Failure strengths of the M21 matrix (superscript m) and M21/35\%/198/T800S CFRP plies (superscript $\mathrm{p}$ ). Tension and compression are indicated respectively by $\mathrm{T}$ and $\mathrm{C}$ in subscript.

\begin{tabular}{cccccccc}
\hline $\begin{array}{c}X_{\mathrm{T}}^{\mathrm{m}} \\
(\mathrm{MPa})\end{array}$ & $\begin{array}{c}S^{\mathrm{m}} \\
(\mathrm{MPa})\end{array}$ & $\begin{array}{c}X_{\mathrm{T} 1}^{\mathrm{p}} \\
(\mathrm{MPa})\end{array}$ & $\begin{array}{c}X_{\mathrm{T} 2}^{\mathrm{p}} \\
(\mathrm{MPa})\end{array}$ & $\begin{array}{c}X_{\mathrm{C} 1}^{\mathrm{p}} \\
(\mathrm{MPa})\end{array}$ & $\begin{array}{c}X_{\mathrm{C} 2}^{\mathrm{p}} \\
(\mathrm{MPa})\end{array}$ & $\begin{array}{c}S_{12}^{\mathrm{p}} \\
(\mathrm{MPa})\end{array}$ & $\begin{array}{c}S_{23}^{\mathrm{p}} \\
(\mathrm{MPa})\end{array}$ \\
\hline $60[15]$ & $60[15]$ & $3000[13,14]$ & $60^{(\star)}$ & $1650[13]$ & $150^{(\star)}$ & $95[13]$ & $60^{(\star)}$ \\
\hline
\end{tabular}

${ }^{(\star)}$ Estimated value.

Table 4: Fracture toughnesses of the M21 matrix (superscript m) and M21/35\%/198/T800S CFRP plies (superscript $\mathrm{p}$ ). Tension and compression are indicated respectively by $\mathrm{T}$ and $\mathrm{C}$ in subscript.

\begin{tabular}{cccccc}
\hline $\begin{array}{c}\mathcal{G}_{\mathrm{I}}^{\mathrm{m}} \\
\left(\mathrm{kJ} / \mathrm{m}^{2}\right)\end{array}$ & $\begin{array}{c}\mathcal{G}_{\mathrm{II}}^{\mathrm{m}} \\
\left(\mathrm{kJ} / \mathrm{m}^{2}\right)\end{array}$ & $\begin{array}{c}\mathcal{G}_{\mathrm{T} 1}^{\mathrm{p}} \\
\left(\mathrm{kJ} / \mathrm{m}^{2}\right)\end{array}$ & $\begin{array}{c}\mathcal{G}_{\mathrm{T} 2}^{\mathrm{p}} \\
\left(\mathrm{kJ} / \mathrm{m}^{2}\right)\end{array}$ & $\begin{array}{c}\mathcal{G}_{\mathrm{C} 1}^{\mathrm{p}} \\
\left(\mathrm{kJ} / \mathrm{m}^{2}\right)\end{array}$ & $\begin{array}{c}\mathcal{G}_{\mathrm{C} 2}^{\mathrm{p}} \\
\left(\mathrm{kJ} / \mathrm{m}^{2}\right)\end{array}$ \\
\hline $0.75[15]$ & $1.25[15]$ & $240[16]$ & $1.5[14]$ & $50[16]$ & $3.0^{(\star)}$ \\
\hline
\end{tabular}

${ }^{(\star)}$ Estimated value.

Table 5: Mechanical properties of ROHACELL foams. Tension and compression are indicated respectively by $\mathrm{T}$ and $\mathrm{C}$ in subscript.

\begin{tabular}{ccccccc}
\hline Foam type & $\begin{array}{c}\rho^{(\star)} \\
\left(\mathrm{g} / \mathrm{cm}^{2}\right)\end{array}$ & $\begin{array}{c}E^{(\star)} \\
(\mathrm{MPa})\end{array}$ & $\begin{array}{c}\sigma_{\mathrm{C}}^{\mathrm{y}}(\star) \\
(\mathrm{MPa})\end{array}$ & $\begin{array}{c}X_{\mathrm{T}}(\star) \\
(\mathrm{MPa})\end{array}$ & $\begin{array}{c}S^{(\star)} \\
(\mathrm{MPa})\end{array}$ & $\begin{array}{c}\mathcal{G}^{(\dagger)} \\
\mathrm{kJ} / \mathrm{m}^{2}\end{array}$ \\
\hline IG-31 [18] & 0.032 & 36 & 0.4 & 1.0 & 0.4 & 0.10 \\
RIMA-51 [17] & 0.052 & 75 & 0.8 & 1.6 & 0.8 & 0.10 \\
RIMA-71 [17] & 0.075 & 105 & 1.7 & 2.2 & 1.3 & 0.10 \\
\hline
\end{tabular}

${ }^{(\star)}$ From manufacturer.

(†) For mode-I opening of the foam core [19]. 


$$
y(x)=\alpha \cdot L^{\mathrm{w}} \cdot \sin \frac{\pi \cdot x}{L^{\mathrm{w}}} \quad, \quad \text { hence } \quad\left\{\begin{array}{l}
\frac{\mathrm{d} y}{\mathrm{~d} x}=\alpha \cdot \pi \cdot \cos \frac{\pi \cdot x}{L^{\mathrm{w}}} \\
\frac{\mathrm{d}^{2} y}{\mathrm{~d} x^{2}}=-\frac{\alpha \cdot \pi^{2}}{L^{\mathrm{w}}} \cdot \sin \frac{\pi \cdot x}{L^{\mathrm{w}}} .
\end{array}\right.
$$

Let $X_{\infty}$ and $e_{\infty}$ be respectively the remote strength (normalised by the thickness of the composite skins, $\left.2 \cdot t^{\mathrm{W}}\right)$ and failure strain of the wavy-ply structure. Failure will ideally occur when the wavy skins are completely flattened (i.e. the foam core is completely crushed and the deflection is $v(x)=-y(x))$, under the combination of remote tensile stresses $\left(X_{\infty}\right)$ and maximum bending stresses $\left(\sigma_{\mathrm{B}}^{\max }\right)$. If $E_{\mathrm{T} 1}^{\mathrm{p}}$ and $X_{\mathrm{T} 1}^{\mathrm{p}}$ are respectively the stiffness and strength of the composite plies in longitudinal tension, then $X_{\infty}$ must satisfy:

$$
X_{\mathrm{T} 1}^{\mathrm{p}}=X_{\infty}+\sigma_{\mathrm{B}}^{\max }, \quad \text { with } \quad \sigma_{\mathrm{B}}^{\max }=\left.\frac{t^{\mathrm{w}}}{2} \cdot \frac{\mathrm{d}^{2} y}{\mathrm{~d} x^{2}}\right|^{\max } \cdot E_{\mathrm{T} 1}^{\mathrm{p}} .
$$

The overall strain will have contributions from the extension and the unfolding of the skins. If $s^{\mathrm{w}}$ is the half-wave arc-length, then $e_{\infty}$ will be:

$$
e_{\infty}=\frac{X_{\infty}}{E_{\mathrm{T} 1}^{\mathrm{p}}}+\frac{s^{\mathrm{w}}-L^{\mathrm{w}}}{L^{\mathrm{w}}+L^{\mathrm{b}}}, \quad \text { with } \quad s^{\mathrm{w}}=2 \cdot \int_{x=0}^{L^{\mathrm{w}} / 2} \sqrt{1+\left(\frac{\mathrm{d} y}{\mathrm{~d} x}\right)^{2}} \mathrm{~d} x
$$

Replacing the derivatives shown in Equation 1 into Equation 2 and rearranging, the remote strength and failure strain of the wavy-ply sandwich structure come as:

$$
\begin{aligned}
X_{\infty} & =X_{\mathrm{T} 1}^{\mathrm{p}}-\frac{t^{\mathrm{w}}}{L^{\mathrm{w}}} \cdot \frac{\alpha \cdot \pi^{2}}{2} \cdot E_{\mathrm{T} 1}^{\mathrm{p}}, \\
e_{\infty} & =\frac{X_{\mathrm{T} 1}^{\mathrm{p}}}{E_{\mathrm{T} 1}^{\mathrm{p}}}-\frac{t^{\mathrm{w}}}{L^{\mathrm{w}}} \cdot \frac{\alpha \cdot \pi^{2}}{2}+\frac{L^{\mathrm{w}}}{L^{\mathrm{w}}+L^{\mathrm{b}}} \cdot\left[\frac{2 \cdot \sqrt{1+\alpha^{2} \cdot \pi^{2}}}{\pi} \cdot \mathcal{E}\left(\frac{\alpha \cdot \pi}{\sqrt{1+\alpha^{2} \cdot \pi^{2}}}\right)-1\right],
\end{aligned}
$$

where $\mathcal{E}(k)=\int_{0}^{\pi / 2} \sqrt{1-k^{2} \cdot \sin ^{2}(\theta)} \mathrm{d} \theta$ is the complete elliptic integral of second kind.

\subsubsection{Results and selection of wave geometry}

Figure 3 presents the remote strength and failure strain of different wavy-ply sandwich configurations (as predicted by Equation 3), showing that:

- Increasing the aspect-ratio $\alpha$ leads to higher failure strains (due to larger excess length in Equation $3 \mathrm{~b}$ ) at the expense of strength (due to larger bending stresses in Equation 3a);

- Increasing the ply thickness $t^{\mathrm{w}}$ (Figure 3a vs. 3b) amplifies bending stresses (see Equation 3a), which considerably weakens the structure and slightly reduces ductility;

- Decreasing the bridging length $L^{\mathrm{b}}$ (Figure 3a vs. 3c) increases slightly the remote failure strain (see Equation 3b), without affecting the strength. 


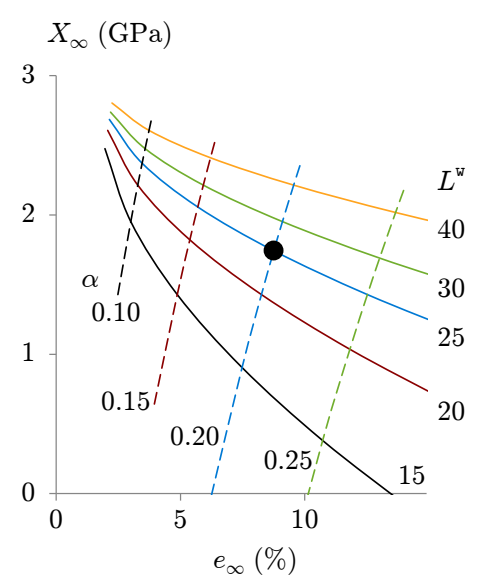

(a) $L^{\mathrm{b}}=5.0 \mathrm{~mm}, t^{\mathrm{w}}=1 \cdot t^{\mathrm{P}}$.

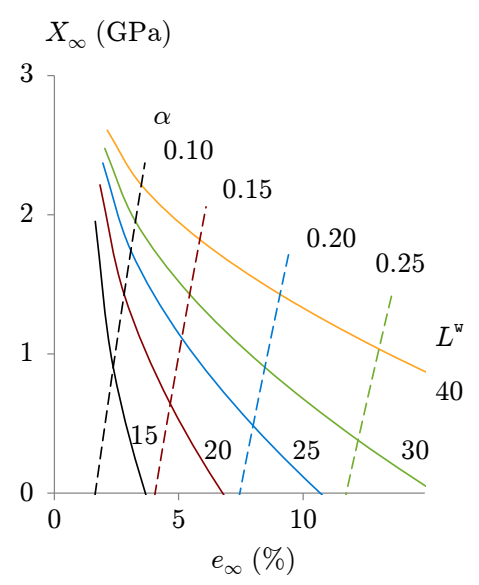

(b) $L^{\mathrm{b}}=5.0 \mathrm{~mm}, t^{\mathrm{w}}=2 \cdot t^{\mathrm{p}}$.

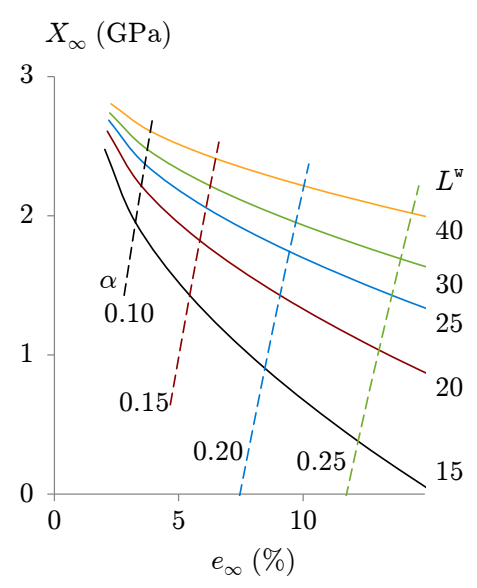

(c) $L^{\mathrm{b}}=2.5 \mathrm{~mm}, t^{\mathrm{w}}=1 \cdot t^{\mathrm{p}}$.

Figure 3: Results from the analytical modelling for designing the wavy profile $\left(t^{\mathrm{P}}=0.193 \mathrm{~mm}\right)$. The selected configuration (see Table 6) is shown as • in Figure 3a.

Figure 3 shows that a reasonable balance between strength and failure strain requires intermediate wave aspect-ratios, thin skins (small $t^{\mathrm{W}} / L^{\mathrm{w}}$ ) and short bridging regions (small $\left.L^{\mathrm{b}} / L^{\mathrm{w}}\right)$. The wave profile highlighted in Figure $3 \mathrm{a}$ and described in Table 6 was therefore selected. In this configuration, each skin is one-ply thick, and the wave profile and bridging region are sufficiently large to be manufactured with reasonable precision; moreover, it is possible to fit 3 full wavelengths within a $240 \mathrm{~mm}$ long specimen (including grips), so that diffuse damage in a series of wavy-cells can be experimentally verified (see Section 4).

\subsection{Finite element simulations and detailed design}

\subsubsection{Model definition}

Nominal geometry and boundary conditions. The tensile response of the wavy-ply sandwich structure was simulated using the FE package Abaqus [20]. Due to symmetry, only a quarter of the wavy-cell was modelled, with boundary conditions as represented in Figure 4a. The outer skin contour was defined by the sinusoidal profile previously selected (see Equation 1 and Table 6), and a constant skin thickness was assumed.

A fillet of epoxy resin was added to the ends of the bridging region (see Figures 2 and $4 \mathrm{~b}$ ) to avoid premature failure due to delamination. The fillet was modelled with a circular profile,

Table 6: Design parameters for the wavy-ply sandwich concept.

\begin{tabular}{ccccc|ccc}
\hline \multicolumn{4}{c|}{ From analytical model (Section 3.1) } & \multicolumn{3}{c}{ From FE simulations (Section 3.2) } \\
$t^{\mathrm{w}}(\mathrm{mm})$ & $L^{\mathrm{w}}(\mathrm{mm})$ & $\alpha(-)$ & $A^{\mathrm{w}}(\mathrm{mm})$ & $L^{\mathrm{b}}(\mathrm{mm})$ & $t^{\mathrm{f}}(\mathrm{mm})$ & $\beta^{\mathrm{f}}\left({ }^{\circ}\right)$ & $\begin{array}{c}\text { ROHACELL } \\
\text { foam }\end{array}$ \\
\hline 0.193 & 25 & 0.20 & 5.0 & 5.0 & 0.5 & 30 & RIMA-51 \\
\hline
\end{tabular}




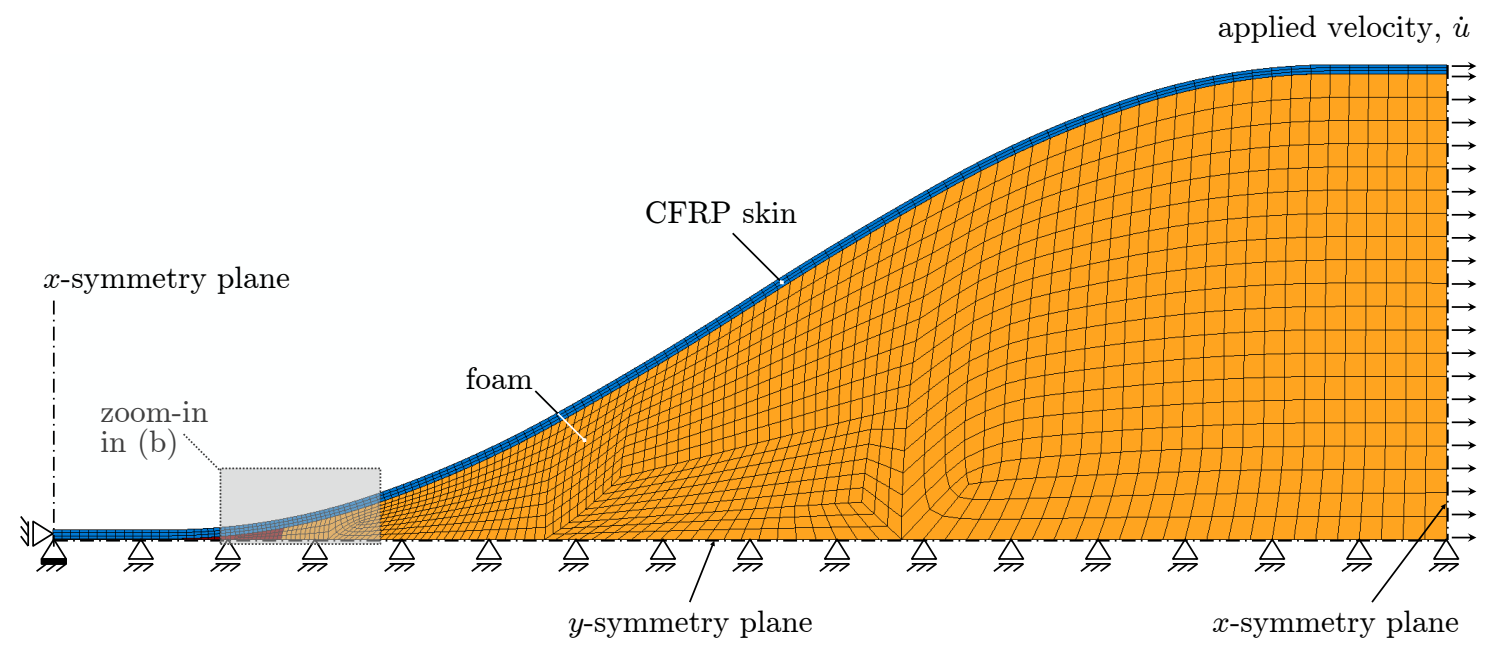

(a) Geometry, boundary conditions and mesh.

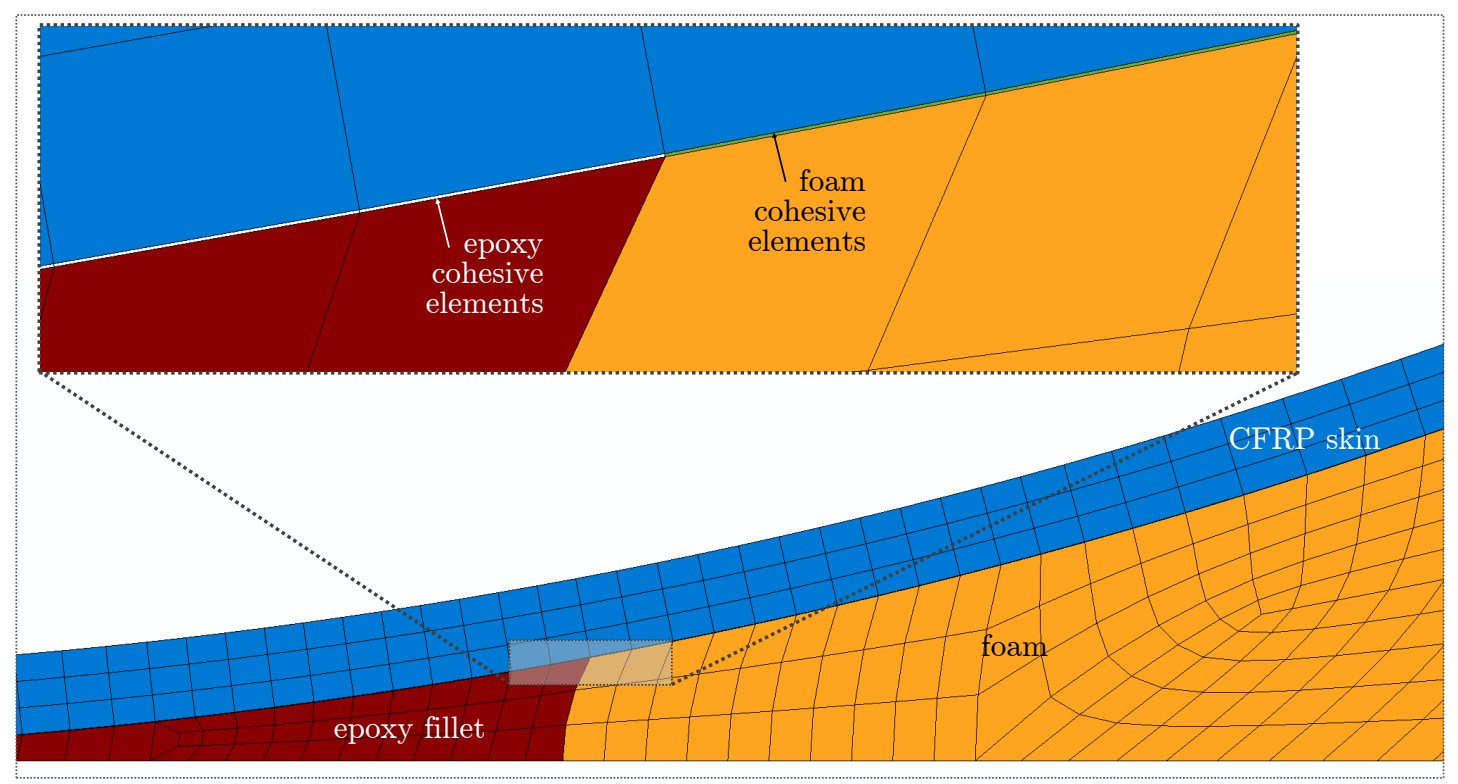

(b) Detail of the resin fillet (zoom-in from Figure 4a).

Figure 4: Overview of the FE model (with optimised geometry, as described in Table 6).

and its thickness $\left(t^{\mathrm{f}}\right)$ and angle $\left(\beta^{\mathrm{f}}\right)$ were selected through parametric studies (detailed in Section 3.2.3); the optimised fillet geometry is shown in Table 6 .

Material and damage modelling. The CFRP in the wavy skins was modelled as an orthotropic material with linear-elasticity and Hashin's failure criteria for damage initiation and propagation [20]. Input mechanical properties are shown in Tables 2 to 4; the toughness values used in the FE analyses were halved from the values in Table 4, since failure occurred near $x$ - and $y$-symmetry planes (close to the epoxy fillet). 
The core material was modelled with isotropic linear-elasticity and crushable foam plasticity with volumetric hardening [20], using the mechanical properties shown in Tables 5 and 7 and the hardening response in Figure 5 (Appendix A details the plasticity model and the derivation of input properties in Table 7). Three foam densities were considered, and the most suitable one was selected through FE analysis (see Section 3.2.3). Potential skin-core debonding was modelled with cohesive elements (see Figure 4b) assigned with foam properties and quadratic interaction for stress components [20].

The epoxy resin in the bridging region and fillet (see Figure 4b) was modelled as an isotropic linear-elastic material. A layer of cohesive elements [20] was added between the CFRP skins and the epoxy fillet to allow for debonding and delamination. Mechanical properties for the epoxy elements are shown in Tables 2-4; input toughness values were halved to account for the $y$-symmetry plane in the FE model.

Numerical analysis. The nominal FE mesh is shown in Figure 4, analysed assuming plane stress conditions (except for the foam, which had to be modelled by plane-strain elements, with zero Poisson's ratio and enhanced hourglass control). The models were run in Abaqus Explicit [20], by imposing a deformation of $\dot{u}=0.01 \mathrm{~mm} / \mathrm{s}$ (see Figure 4a). Uniform mass scaling was independently applied to each material type (CFRP skins, foam core, epoxy fillet

Table 7: Input properties for modelling ROHACELL $[17,18]$ foams in Abaqus [20] (see Appendix A).

\begin{tabular}{rccccc}
\hline Foam type & $k(-)$ & $k_{\mathrm{T}}(-)$ & $\varepsilon_{\mathrm{C}}^{\mathrm{h}}(-)$ & $a_{2}(\mathrm{MPa})$ & $a_{3}(\mathrm{MPa})$ \\
\hline IG-31 & 2.09 & 7.26 & 0.60 & 22 & 119.6 \\
RIMA-51 & 2.19 & 3.19 & 0.60 & 22 & 182.1 \\
RIMA-71 & 1.73 & 1.65 & 0.60 & 22 & 38.3 \\
\hline
\end{tabular}

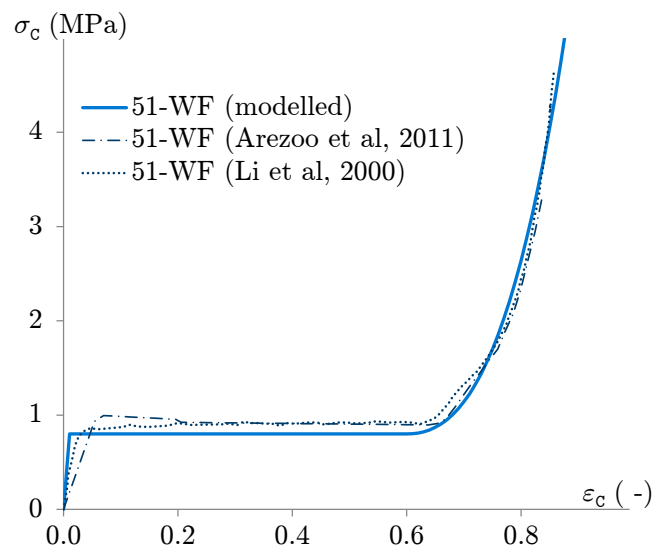

(a) Baseline foam $(51-\mathrm{WF})$.

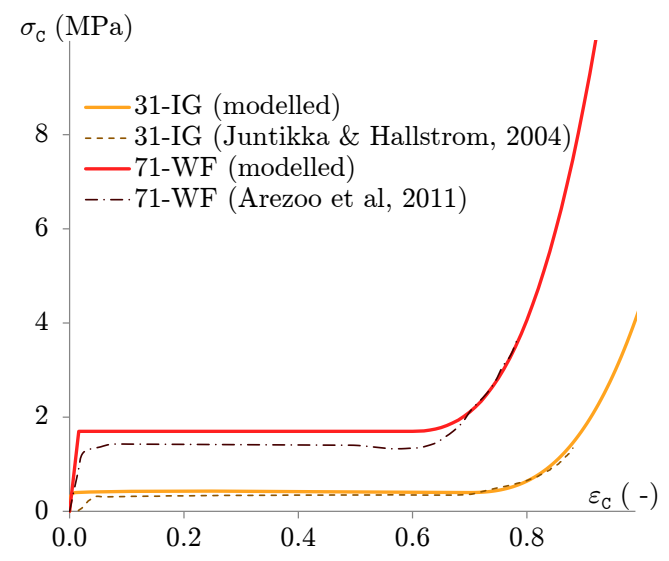

(b) Alternative foams (31-IG and 71-WF).

Figure 5: Engineering compressive stress-strain curves for ROHACELL foams: experimental (from literature [21-23]) and modelled. Full constitutive curves were not available for RIMA foams, so curves for the corresponding IG [18] or WF [24] foam type are used instead. 
and cohesive elements) at the beginning of the analysis, targeting a global time increment of $10^{-5} \mathrm{~s}$. It was confirmed that the effects of mesh refinement, kinetic energy and viscous dissipation were negligible (see Figure 6b, and Figure 8a in Section 3.2.3).

\subsubsection{FE simulation results for the optimised configuration}

Figures 6 and 7 show the results of the FE simulation for the optimised wavy-ply sandwich structure (defined in Table 6). The following sequence of events is predicted:

1. Linear response before the symbol $\square$ in Figure 6a;

2. Onset of plasticity in the foam core, highlighted as $\square$ in Figure 6a. Plastic deformation propagates across the height of the foam cell (see Figure $7 \mathrm{a}$ and $7 \mathrm{~b}$ ), and strains localise in bands due to the stress plateau in the response of the foam;

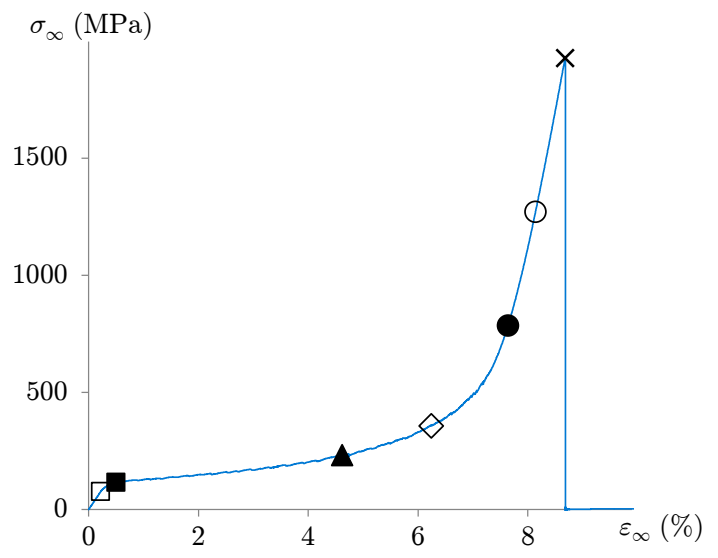

$\times$ skin longitudinal tensile failure oskin at $75 \%$ of longitudinal failure criterion

- skin at $50 \%$ of longitudinal failure stress $\diamond$ onset of foam strain-hardening

$\Delta$ maximum opening of core-skin interface

- onset of cohesive damage

$\square$ onset of foam plasticity

(a) Overall stress-strain curve.

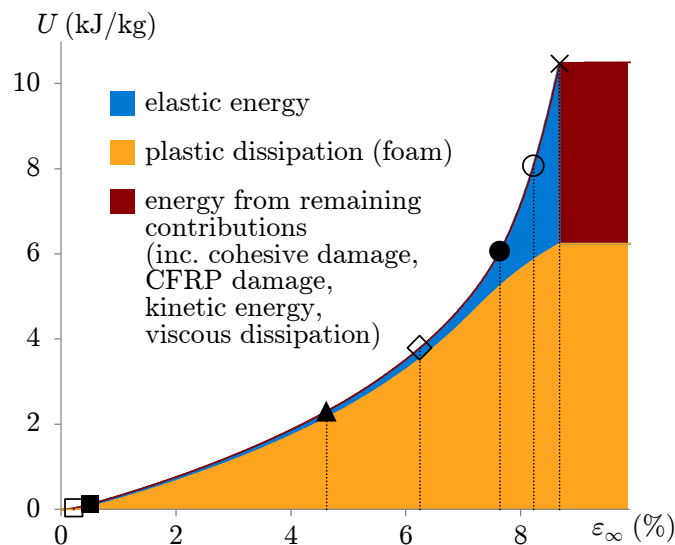

(b) Energy components.

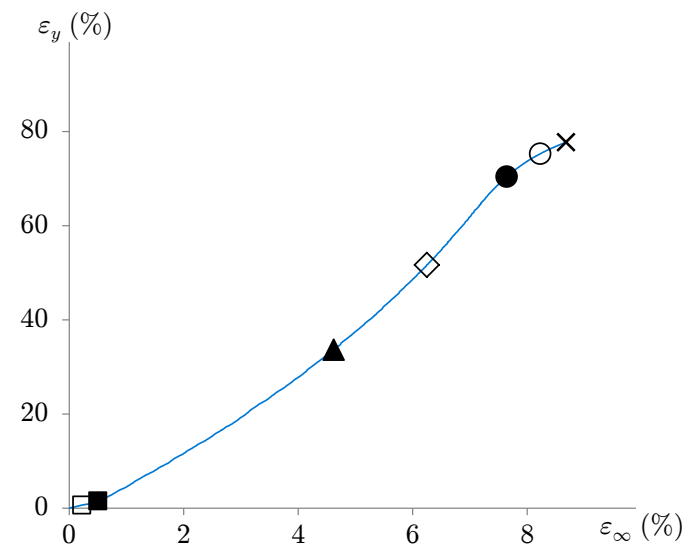

(c) Average transverse compression at the foam.

Figure 6: Overall response predicted by the FE analysis of the nominal wavy-ply sandwich configuration. 


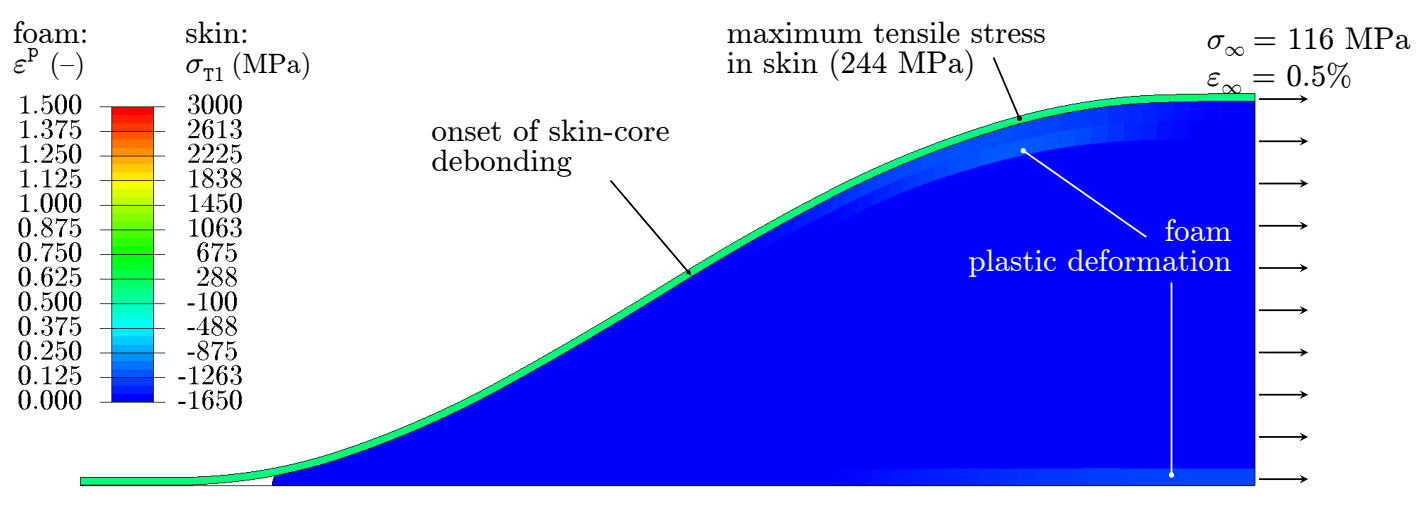

(a) At the onset of cohesive damage ( $\boldsymbol{\square}$ in Figure 6a).

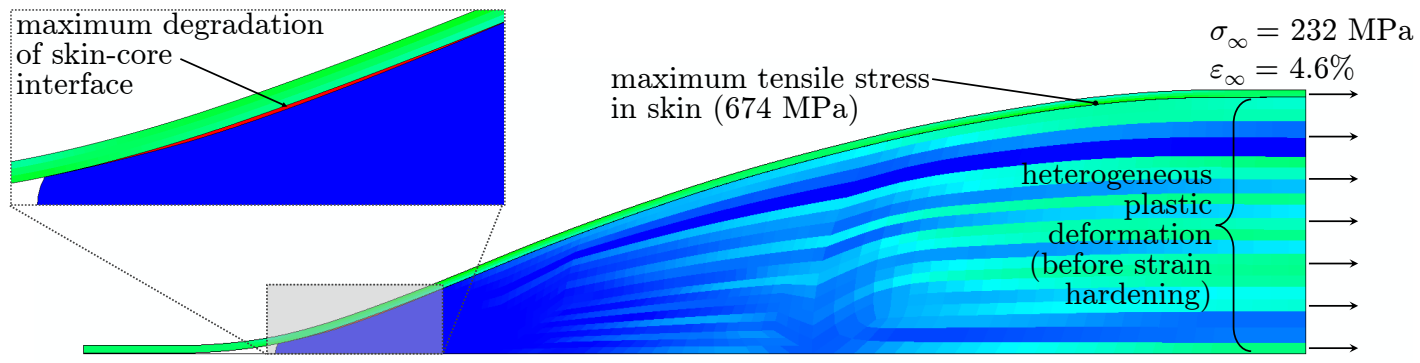

(b) At maximum opening of the core-skin interface ( $\boldsymbol{\Delta}$ in Figure 6a).

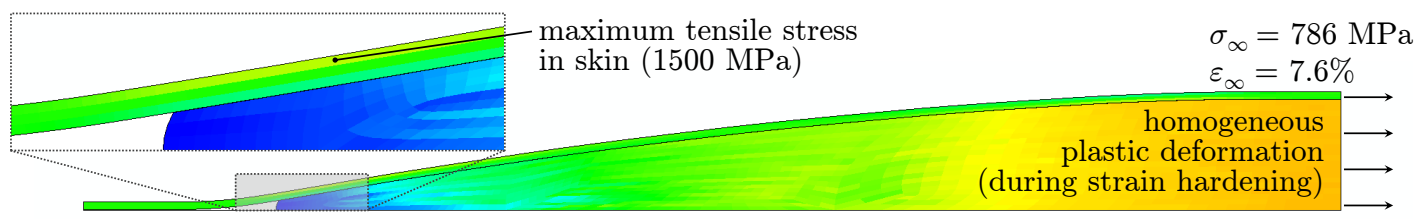

(c) At $25 \%$ of the skin longitudinal failure criterion ( in Figure $6 a)$.

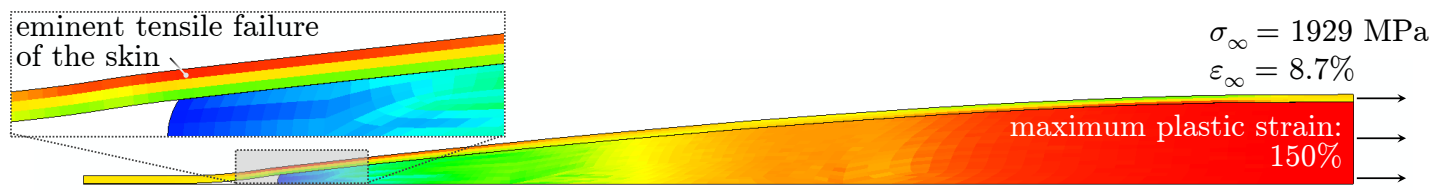

(d) Immediately before longitudinal tensile failure of the skin $(X$ in Figure $6 a)$.

Figure 7: Deformed shape, equivalent plastic strains in the foam core, and longitudinal stresses in the CFRP skin, as predicted by the $\mathrm{FE}$ analysis for the nominal wavy-ply sandwich configuration.

3. Degradation of the skin-core interface (between symbols $\boldsymbol{\square}$ and $\boldsymbol{\Delta}$ in Figure 6a), as shown in Figures $7 \mathrm{a}$ and $7 \mathrm{~b}$. The skin-core interface does not debond completely, and begins closing after the point $\boldsymbol{\Delta}$ in Figure 6a;

4. Strain hardening of the foam core under compression (after the symbol $\diamond$ in Figure 6a), developing a smooth crushing strain field (see Figures $7 \mathrm{c}$ and $7 \mathrm{~d}$ ); 
5. Extension of the CFRP skin with progressive increase of the remote load (after the symbol $\diamond$ in Figure 6a). The strain hardening in the global stress-strain curve is due to strain-hardening of the foam and re-alignment of the fibres along the loading direction. The final tangent stiffness reaches nearly $80 \%$ of the CFRP ply stiffness;

6. Catastrophic failure of the CFRP skins (highlighted as $X$ in Figure 6a). Tensile failure (due to remote and bending stresses) is triggered at the outer surface of the skin near the the epoxy fillet (see Figure 7d), and propagates unstably across the skin thickness.

\subsubsection{Parametric studies and optimisation}

Numerical parameters. Figure 8a shows the effect of mesh refinement and mass scaling on the predicted response of the nominal configuration (analysed in Section 3.2.2). Decreasing the mass scaling by a factor of $\sqrt{10}$ (see lower mass scaling curve) did not affect predictions,

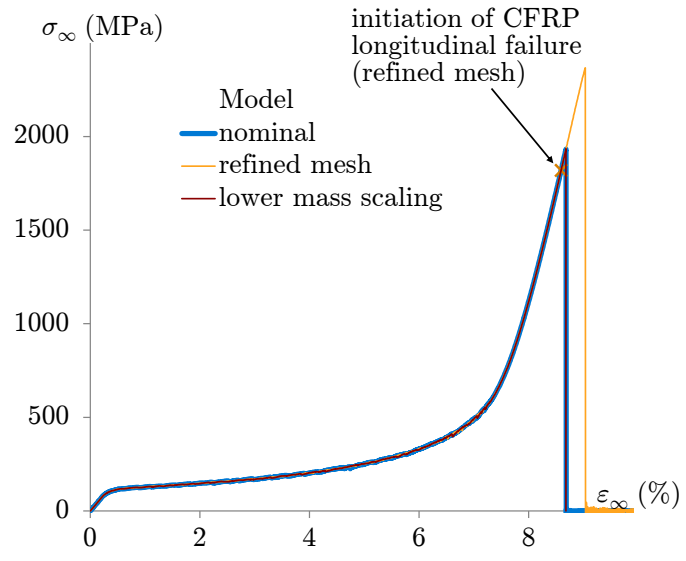

(a) Numerical parameters.

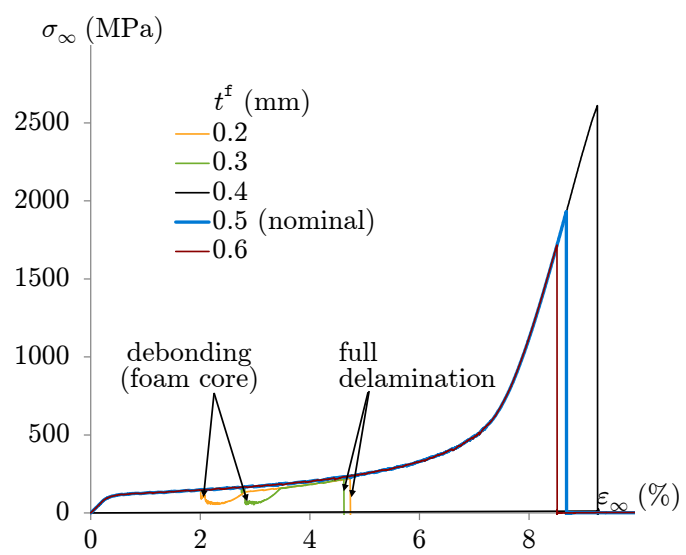

(c) Fillet thickness.

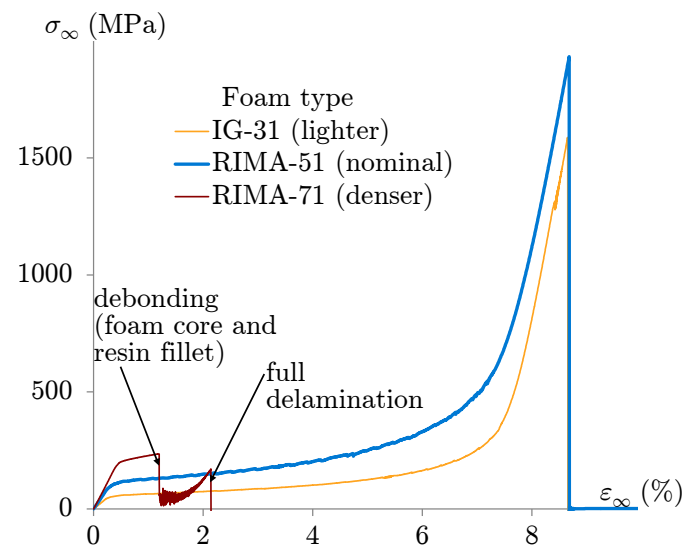

(b) Foam type.

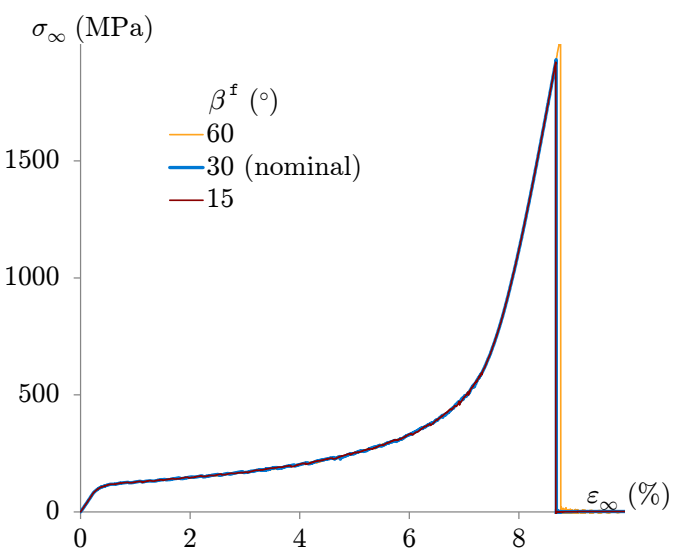

(d) Fillet angle.

Figure 8: Effect of numerical and physical parameters on the predicted stress-strain response of wavy-ply sandwich structures. The nominal configuration was analysed in Section 3.2.2. 
which is corroborated by the negligible levels of kinetic energy shown in Figure 6b. The FE model with refined mesh predicted a delayed final failure relative to the nominal model, due to stable damage accumulation in the CFRP skin in the former; all other aspects of the mechanical response were unaffected by mesh refinement.

Foam type. The effect of varying the core material is presented in Figure $8 \mathrm{~b}$. Using a lighter foam (IG-31) did not affect the sequence of events described in Section 3.2.2, but it reduced the support provided to the composite skins. Consequently, lower initial stiffness, yield stress and ultimate strength were predicted for the sandwich structure with lighter foam core.

Increasing the density of the foam core (RIMA-71 in Figure 8b) delayed the onset of core crushing, thus increasing the initial stiffness and yield stress of the sandwich structure. However, this aggravated the degradation of the skin-foam interface in comparison to the nominal configuration (see Figure $7 \mathrm{~b}$ ) and led to full delamination of the bridging region.

Geometry of the resin fillet. Figures $8 \mathrm{c}$ and $8 \mathrm{~d}$ show the influence of the epoxy fillet on the response of the wavy-ply structure. A very thin fillet $\left(t^{\mathrm{f}}=0.2\right.$ to $0.3 \mathrm{~mm}$ in Figure $8 \mathrm{c}$ ) is unable to arrest degradation of the skin-core interface and delamination of the bridging

region. It was predicted that this failure mode can be avoided by using fillets with $t^{f} \geq 0.4 \mathrm{~mm}$; however, increasingly thicker fillets create larger bending stresses, thus reducing slightly the ultimate strength of the sandwich structure (see curves for $t^{\mathrm{f}}=0.4$ to $0.6 \mathrm{~mm}$ in Figure 8c).

Figure $8 \mathrm{~d}$ shows that the angle of the resin fillet ( $\beta^{\mathrm{f}}$ in Figure 2 ) has a negligible influence on the response of the wavy-ply sandwich structure.

\section{Experimental procedure}

\subsection{Manufacturing}

In order to demonstrate the wavy-ply sandwich concept developed in Section 3, specimens for tensile testing were manufactured by (see Figures 9 and 10):

1. Machining 2 aluminium half moulds with the wavy profile defined in Section 3.1;

2. Preparing RIMA-51 cells by heat-treating the foam [25] and machining the wavy profile (including the fillet geometry) previously defined;

3. Preparing epoxy fillets by manually moulding uncured M21 resin film into the approximate shape shown in Figure 4b (see Table 8 for different strategies employed);

4. Laying-up a sandwich panel as shown in Figure 9, and curing it in the autoclave [13];

5. End-tabbing the panel and cutting specimens as shown in Figure 10.

Two sets of specimens (A and B) were manufactured, differing in (i) the finishing of the edges of the foam cells, and (ii) the manually-formed resin fillet (see Table 8). The 


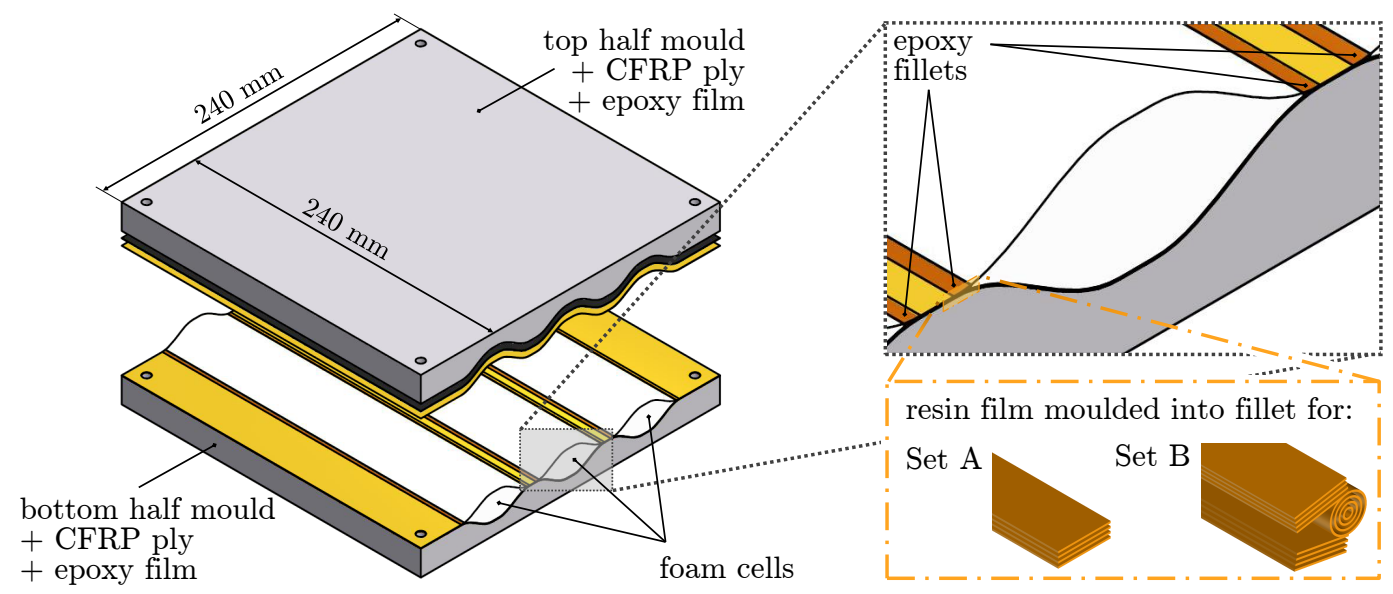

Figure 9: Schematic lay-up of a wavy-ply sandwich panel (details for resin fillets are given in Table 8).

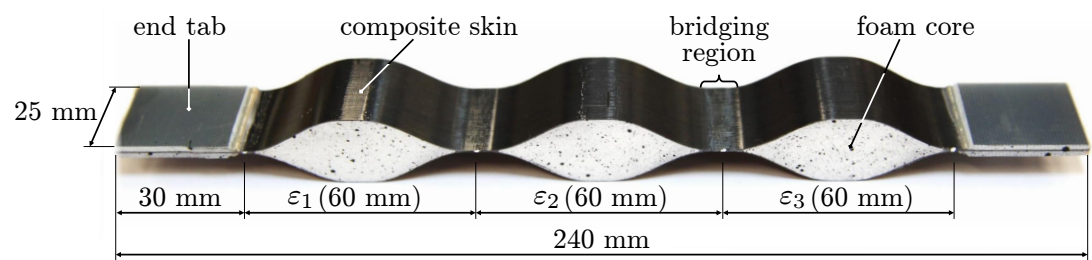

Figure 10: Wavy-ply sandwich specimen: dimensions and definition of strain measurements.

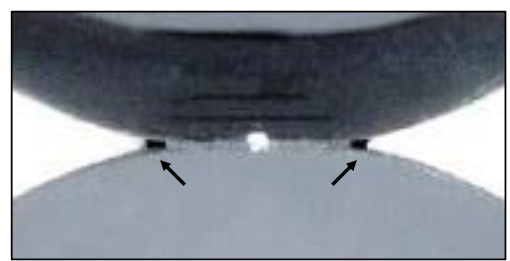

(a) Defective specimen with voids.

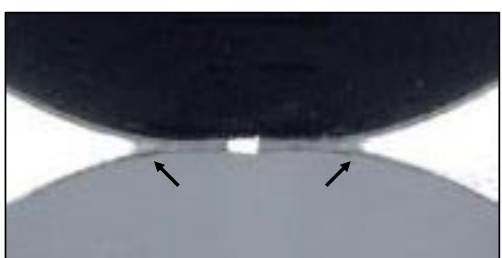

(b) Specimen without voids.

Figure 11: Representative bridging regions of manufactured specimens, showing voids in defective specimens.

modifications implemented for Set B were aimed at reducing void formation in the fillet region, which had been previously observed in Set A (as shown in Figure 11a).

\subsection{Mechanical testing}

Specimens (see Figure 10) were loaded under tension at $1 \mathrm{~mm} / \mathrm{min}$ until longitudinal failure of the skins or premature delamination of the bridging region. Remote stresses were calculated as $\sigma_{\infty}=P /\left(w_{\text {spec }} t_{\text {nom }}\right)$, where $P$ is the overall load, $w_{\text {spec }}$ is the measured specimen width, and $t_{\text {nom }}=0.386 \mathrm{~mm}$ is the nominal thickness of the bridging region (corresponding to two composite plies). The strains of each wavelength $\left(\varepsilon_{1}, \varepsilon_{2}\right.$, and $\varepsilon_{3}$ shown in Figure 10) were measured using a video extensometer system. 
Table 8: Specifications of the two sets of specimens manufactured and tested.

\begin{tabular}{|c|c|c|c|c|c|}
\hline Set & $\begin{array}{l}\text { Edges of foam cells } \\
\text { (and fillet thickness) }\end{array}$ & $\begin{array}{l}\text { Epoxy fillet } \\
\text { (see Figure } 9)\end{array}$ & $\begin{array}{l}\text { No. } \\
\text { specimens }\end{array}$ & $\begin{array}{c}\text { Voids at epoxy } \\
\text { fillet }\end{array}$ & $\begin{array}{l}\text { Predominant } \\
\text { failure mode }\end{array}$ \\
\hline A & $\begin{array}{l}\text { as machined } \\
\left(t^{f}=0.5 \mathrm{~mm}\right)\end{array}$ & $\begin{array}{l}1 \times \text { stack of } 4 \times 4 \mathrm{~mm} \\
\text { wide film }\end{array}$ & 7 & $\begin{array}{l}\text { visible in most } \\
\text { specimens } \\
\text { (Figure 11a) }\end{array}$ & $\begin{array}{l}\text { premature } \\
\text { delamination at } \\
\text { bridging region }\end{array}$ \\
\hline B & $\begin{array}{l}\text { manually sanded } \\
\left(t^{f}>0.5 \mathrm{~mm}\right)\end{array}$ & $\begin{array}{l}2 \times \text { stacks of } 4 \times 4 \mathrm{~mm} \\
\text { wide film }+ \\
1 \times \text { rolled-up } 15 \mathrm{~mm} \text { strip }\end{array}$ & 8 & $\begin{array}{l}\text { no voids } \\
\text { visible } \\
\text { (Figure 11b) }\end{array}$ & $\begin{array}{l}\text { longitudinal } \\
\text { tensile failure of } \\
\text { composite skins }\end{array}$ \\
\hline
\end{tabular}

\section{Results from experimental characterisation}

Remote stress-strain curves for all specimens tested are shown in Figure 12 (remote strains, $\varepsilon_{\infty}$, correspond to the average strain at least two wavelengths, see Figure 10). Set A was largely unsuccessful (Figure 12a), with six specimens failing by delamination (Figure 13a) triggered by voids at the bridging region (Figure 11a). Only one specimen (coincidently without any visible voids) of Set A exhibited a ductile response (illustrated in Figure 13b).

Avoiding void formation in Set B (see Section 4.1) resulted in six (out of eight) successful tests (Figure 12b). The statistics for the initial stiffness $\left(E_{0}\right)$, ultimate strength $\left(X_{\infty}\right)$, failure strain $\left(e_{\infty}\right)$ and specific work of fracture $(U)$ of valid specimens of Set B are shown in Table 9.

Figure 14 presents the evolution of the side view of a successful wavy-ply specimen with progressive loading, showing how specimens withstood large axial deformations through unfolding of the skins and progressive crushing of the core. Figure $14 \mathrm{f}$ shows that, while the

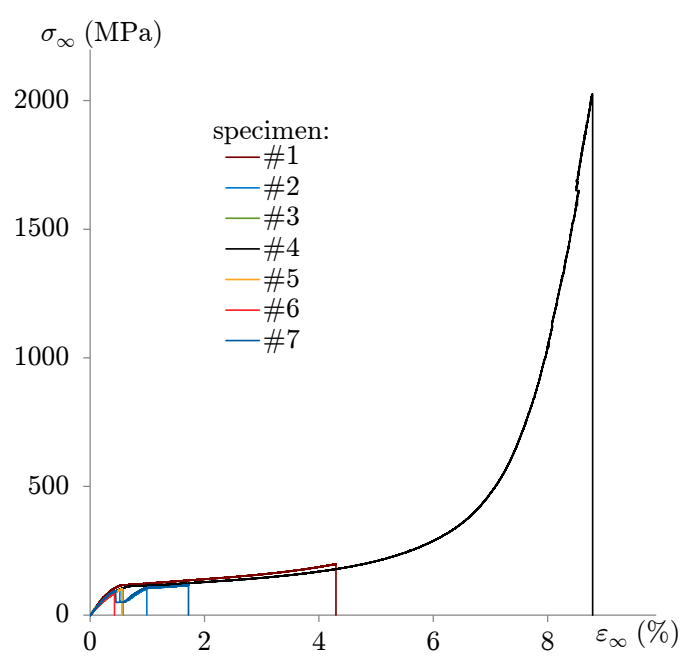

(a) Set A.

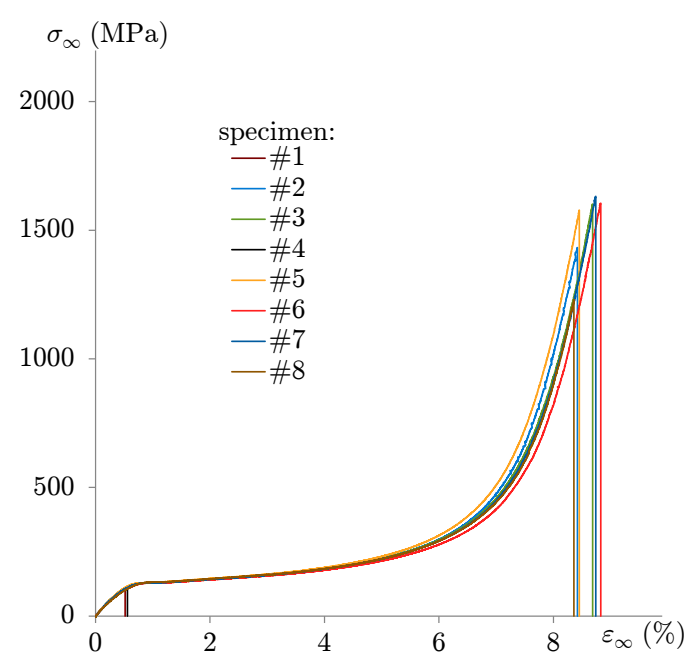

(b) Set B.

Figure 12: Overall stress-strain curves of all wavy-ply specimens tested. 


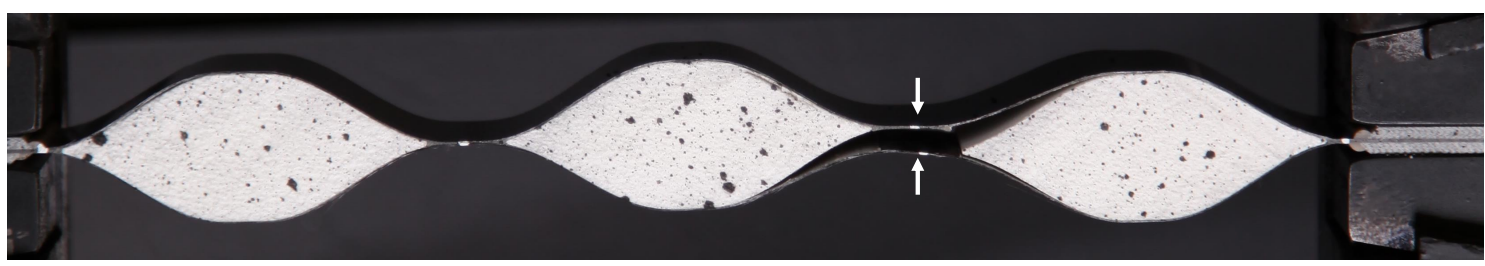

(a) Premature failure by delamination in unsuccessful specimen (B\#4).

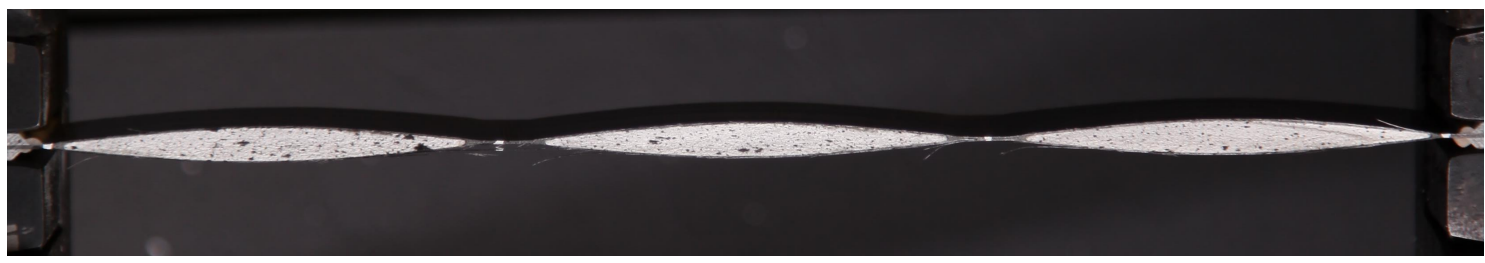

(b) Large deformations in successful specimen (B\#6), immediately before explosive skin failure.

Figure 13: Different failure modes observed in wavy-ply sandwich specimens.

Table 9: Mechanical properties measured for wavy-ply composites (from the six valid tests of Set B).

\begin{tabular}{rcccc}
\hline & $E_{0}$ & $X_{\infty}$ & $e_{\infty}$ & $U^{(\star)}$ \\
\hline Average & $28.4 \mathrm{GPa}$ & $1570 \mathrm{MPa}$ & $8.62 \%$ & $9.35 \mathrm{~kJ} / \mathrm{kg}$ \\
Coefficient of Variation & $2.9 \%$ & $5.0 \%$ & $2.1 \%$ & $9.6 \%$ \\
\hline
\end{tabular}

${ }^{\star}{ }^{\star}$ Estimated assuming an areal weight for the wavy-ply sandwich of $1198 \mathrm{~g} / \mathrm{m}^{2}$, calculated from the densities shown in Table 1 and nominal geometry shown in Figure 4a (hence not considering the gripping regions).

skins deformed elastically, the foam exhibits significant permanent deformation, thus implying a degree of energy absorption during progressive loading.

\section{Discussion}

\subsection{Comparison between FE predictions and experimental results}

Figure 15 compares the stress-strain curves of wavy-ply sandwich specimens with blind predictions from FE simulations. The agreement is remarkable, especially considering the several sources of geometric and material non-linearity in the structure. This suggests that the modelling framework proposed in Section 3 can be used to further develop and optimise the wavy-ply sandwich concept.

The possibility of premature delamination at the bridging region had been predicted by modelling (see FE results for $t^{\mathrm{f}}=0.2 \mathrm{~mm}$ in Figure 15a). Poor resin flow near the edges of the foam cells likely generated the voids shown in Figure 11a, which justifies the discrepancy between the nominal modelling results and most of the specimens from Set A. The one valid experiment from that dataset matches closely the predictions from modelling.

The strength of the valid specimens (i.e. with tensile skin fracture) decreases from Set A to Set B. This is likely due to the increase of fillet size after sanding the edges of the foam 


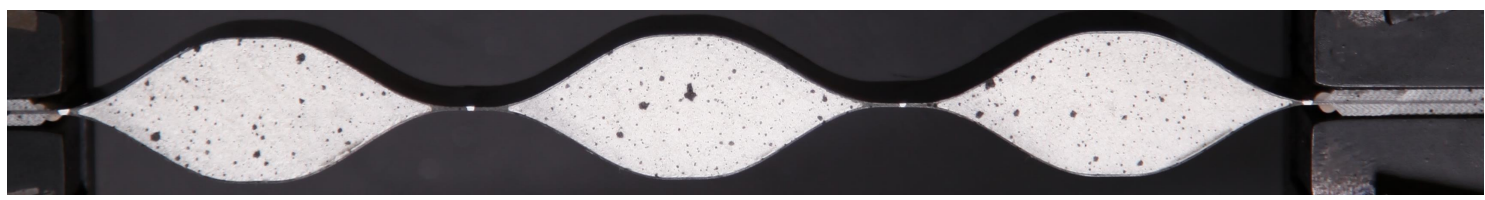

(a) At $\varepsilon_{\infty}=0 \%$.

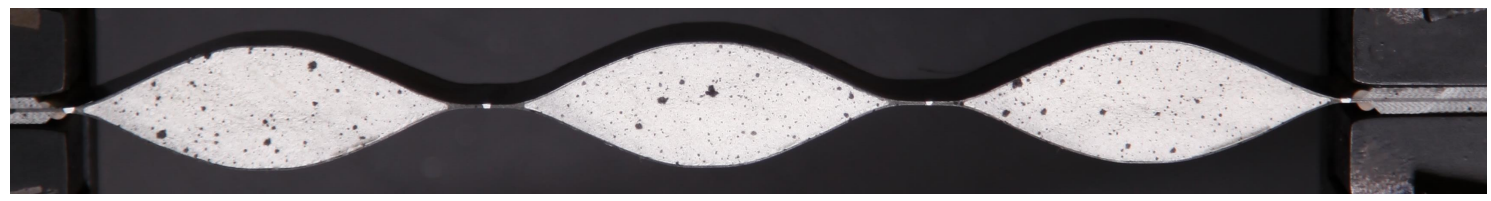

(b) At $\varepsilon_{\infty} \approx 2 \%$.

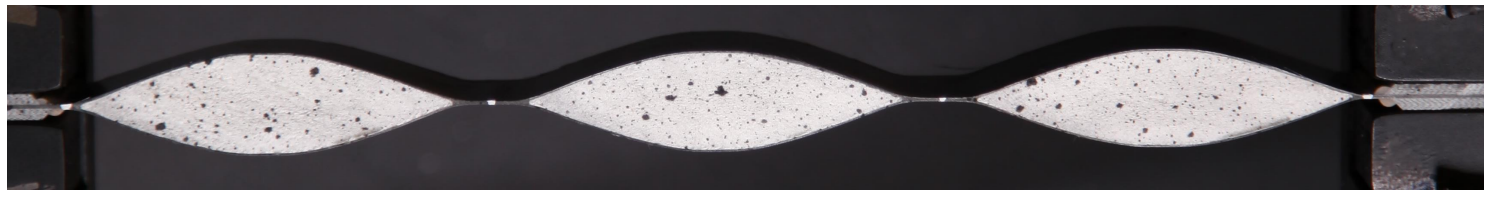

(c) At $\varepsilon_{\infty} \approx 4 \%$.

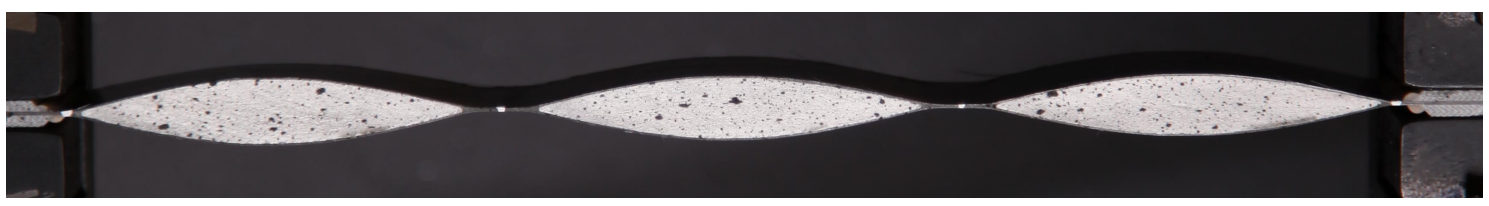

(d) At $\varepsilon_{\infty} \approx 6 \%$.

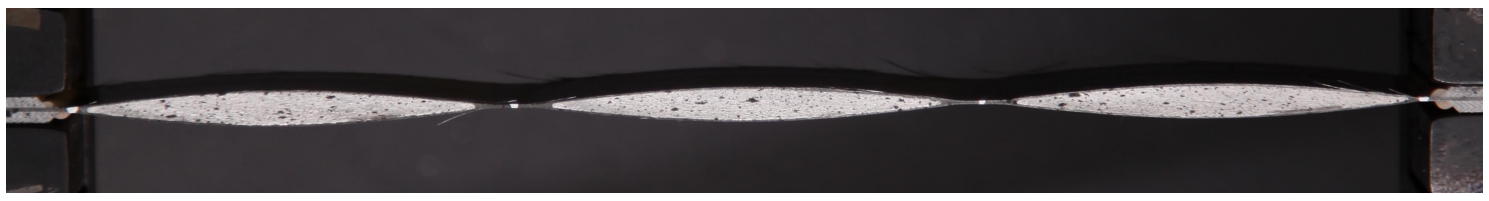

(e) At $\varepsilon_{\infty} \approx 8.5 \%$.

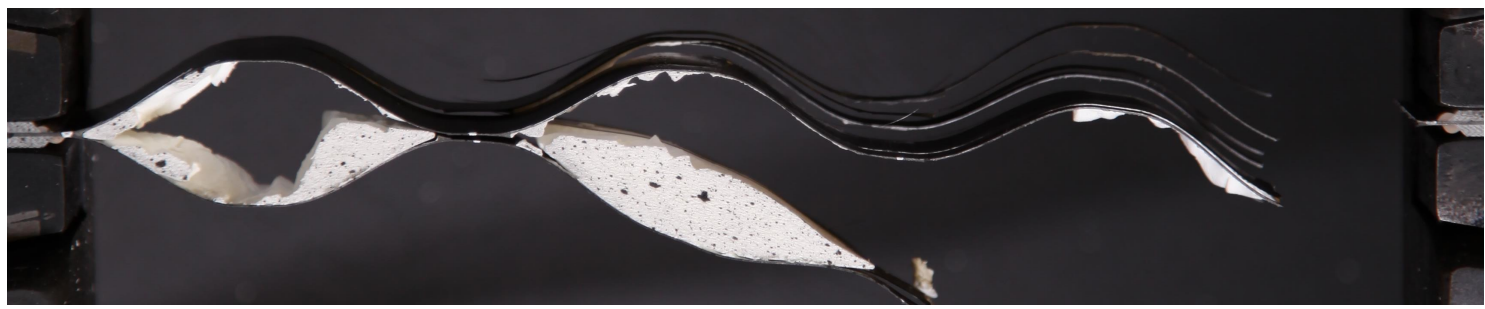

(f) After failure (note the permanent deformation in the central foam cell).

Figure 14: Deformed shape of the side-view of a wavy-ply specimen (B\#3) with progressively increasing remote strain.

cells (see Table 8), which was also predicted by FE (see decreasing strength when going from $t^{\mathrm{f}}=0.5 \mathrm{~mm}$ to $t^{\mathrm{f}}=0.8 \mathrm{~mm}$ in Figure $15 \mathrm{~b}$ ). 


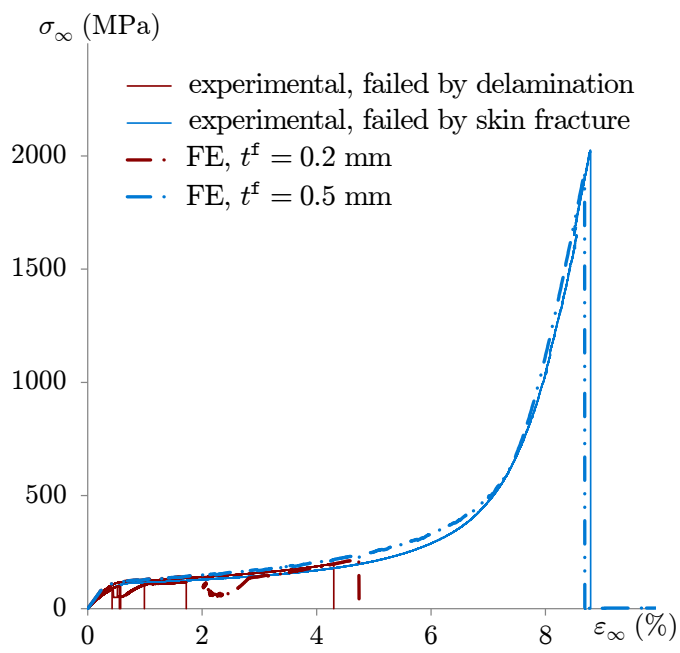

(a) Set A.

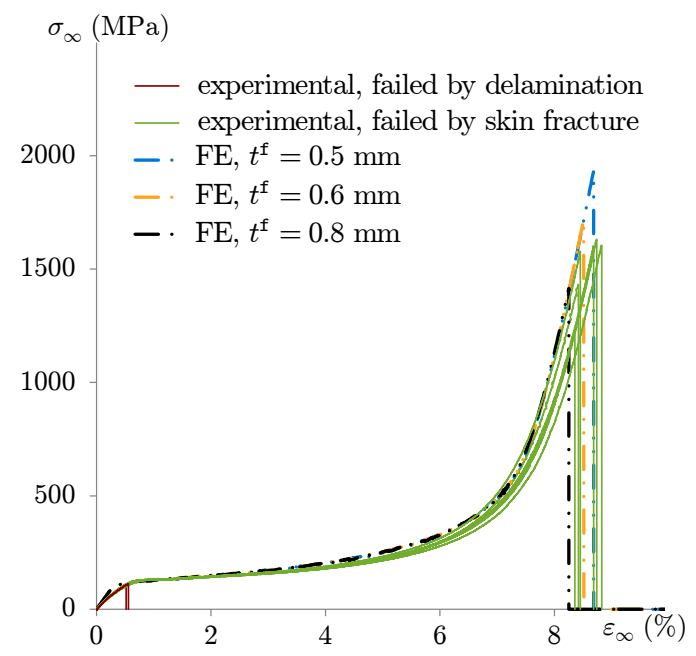

(b) Set B.

Figure 15: Comparison between blind FE predictions (Section 3.2) and experimental results (Section 4).

\subsection{Wavy-ply sandwich concept for enhanced ductility and energy absorption}

Experimental results show that the wavy-ply sandwich concept can increase the failure strain of CFRP plies by nearly one order of magnitude (from $1.82 \%$ to $8.62 \%$ ), and dissipate a considerable amount of energy $(9.35 \mathrm{~kJ} / \mathrm{kg})$ during deformation and failure (see Table 9 ). This is achieved at the cost of initial stiffness (reduced from $165 \mathrm{GPa}$ to 28.4 GPa), ultimate strength (reduced from $3000 \mathrm{MPa}$ to $1570 \mathrm{MPa}$ ), and areal weight (increased from $610 \mathrm{~g} / \mathrm{m}^{2}$ to $1198 \mathrm{~g} / \mathrm{m}^{2}$ ), compared to the equivalent 2-ply CFRP monolithic specimen.

Modelling has shown that the mechanical performance of the wavy-ply sandwich structure can be tailored by adjusting the wave profile, core material and shape of resin fillet:

- Increasing the wave aspect-ratio $\left(\alpha=A^{\mathrm{w}} / L^{\mathrm{w}}\right)$ is beneficial for the failure strain, but detrimental for the strength (see Figure 3 and Equation 3);

- Decreasing the ratio between ply thickness $\left(t^{\mathrm{w}}\right)$ and wavelength $\left(L^{\mathrm{w}}\right)$ increases the overall strength (see Figures 3a-3b and Equation 3a), but also increases the areal weight;

- Using a stiffer and stronger core material increases the initial stiffness and plateau stress of the sandwich structure (see Figure $8 \mathrm{~b}$ ), but also increases the areal weight and the likelihood of premature failure by debonding.

The symmetric wavy-ply concept developed in this paper presents several advantages over the asymmetric wavy-ply sandwich structures proposed in the literature [8-11]:

- The concept proposed in this paper generates a smooth stress-strain response, where the load increases continuously with deformation (see successful specimens in Figure 12b) and the energy is dissipated stably. On the contrary, the asymmetric concept relies on multiple fractures of the straight skin, generating large load drops before final failure; 
- A great component of energy dissipated by the symmetric geometry is actually absorbed through crushing of the core: Figure $6 \mathrm{~b}$ predicts that $6.2 \mathrm{~kJ} / \mathrm{kg}$ are stably absorbed by the foam, which retains significant permanent deformation (as shown in Figure 14f). In the asymmetric geometry, in contrast, most energy is held elastically in the plies, and is suddenly released on failure (which can cause further damage and/or injury);

\subsection{Potential for exploitation and further developments}

The large strains and energy dissipation demonstrated by the wavy-ply sandwich structure (see Table 9) suggest that this concept is particularly interesting for:

(i) blast-protection structures, taking advantage of the high absorption of energy through irreversible deformation of the crushable core;

(ii) protective layers in pressurised vessels, taking advantage of the the large deformations allowed and the detectability of damage by visual inspection.

Further work on the symmetric wavy-ply sandwich concept will focus on:

- Optimising the stiffness, strength, ductility and energy absorption, by modifying the geometry, manufacturing process and materials used. As an example, the failure strains above $8.6 \%$ were measured in specimens with brittle CFRP skins; using high performance ductile fibres (e.g. ultra-high-molecular-weight polyethylene fibres) as skin material can potentially double the measured failure strain;

- Evaluating the effect of the strain-rate on the response (which is especially important for blast applications);

- Improving manufacturability and scalability (e.g. using expandable foams for the core).

- Using multiple plies with different excess lengths in order to increase the initial stiffness and plateau stresses;

- Improving the reliability of the bridging region (e.g. by stitching);

- Extending the concept to two-dimensional loading.

While the wavy-ply sandwich structure is well suited for tensile loading, it relies on the initial waviness of the skins to provide extra length. Consequently, this concept is inappropriate for compression in the longitudinal direction.

\section{Conclusions}

This paper has presented a new wavy-ply sandwich structure developed to achieve large deformations and energy absorption under tensile loading. The concept relies on three components: (i) wavy composite skins (providing excess length and ultimate strength), (ii) a 
crushable foam core (providing initial stiffness and energy absorption), and (iii) bridging regions with resin fillets holding the top and bottom wavy skins together (providing resistance to delamination).

The wave profile was designed using an analytical formulation combining the effect of tension (applied remotely) and bending (from the unfolding of the skins). Finite element analyses supported the selection of the core material and resin fillet geometry, in order to avoid premature failure by delamination in the bridging region. Simulations of the optimised configuration showed the development of large tensile strains and the progressive crushing of the core material.

Wavy-ply sandwich specimens were manufactured using machined moulds and foam cells, with carbon-epoxy skins co-cured in the autoclave. Experimental results from tensile tests showed an excellent correlation with modelling predictions; a first set of defective specimens failed predominantly by premature delamination at the bridging region, but large deformations and high energy dissipation were successfully demonstrated in a second set of specimens with improved manufacturing.

This work demonstrated that wavy-ply sandwich structures with CFRP skins can withstand tensile deformations above $8.6 \%$ and dissipate a specific energy of $9.4 \mathrm{~kJ} / \mathrm{kg}$ under tensile load. Future work will focus on improving these figures further, and exploring the potential of the wavy-ply sandwich concept for blast-protection structures and protective layers in pressurised vessels.

\section{Appendix A. Calibration of crushable foam model}

\section{Appendix A.1. Initial yield surface}

Abaqus's plasticity model for crushable foam with volumetric hardening [20] assumes an elliptical yield surface on the pressure $(p)$ and deviatoric $(q)$ stresses, defined by the yield stress in uniaxial compression $\left(\sigma_{\mathrm{C}}^{\mathrm{y}}\right)$ and the parameters $k$ and $k_{\mathrm{T}}$ :

$$
\left\{\begin{array} { l } 
{ p = - \frac { \sigma _ { 1 } + \sigma _ { 2 } + \sigma _ { 3 } } { 3 } } \\
{ q = \sqrt { \frac { ( \sigma _ { 1 } - \sigma _ { 2 } ) ^ { 2 } + ( \sigma _ { 2 } - \sigma _ { 3 } ) ^ { 2 } + ( \sigma _ { 1 } - \sigma _ { 3 } ) ^ { 2 } } { 2 } } , \quad ( \mathrm { A } . 1 \mathrm { a } ) }
\end{array} \quad \left\{\begin{array}{l}
k=\frac{\sigma_{\mathrm{C}}^{\mathrm{y}}}{p_{\mathrm{C}}^{\mathrm{y}}} \\
k_{\mathrm{T}}=\frac{p_{\mathrm{T}}^{\mathrm{y}}}{p_{\mathrm{C}}^{\mathrm{y}}}
\end{array}\right.\right.
$$

In the previous equation, $p_{\mathrm{C}}^{\mathrm{y}}$ and $p_{\mathrm{T}}^{\mathrm{y}}$ are the absolute values of the pure yield stress under hydrostatic compression and tension respectively. The yield surface is mathematically represented by: 


$$
\left.\Longrightarrow q= \pm r_{q} \cdot \sqrt{1-\left(\frac{p-p_{0}}{r_{p}}\right)^{2}+\left(\frac{q}{r_{q}}\right)^{2}=1}\right)^{2}, \quad \text { with } \quad\left\{\begin{array}{l}
p_{0}=\frac{p_{\mathrm{C}}^{\mathrm{y}}-p_{\mathrm{T}}^{\mathrm{y}}}{2} \\
r_{p}=\frac{p_{\mathrm{C}}^{\mathrm{y}}+p_{\mathrm{T}}^{\mathrm{y}}}{2} \\
r_{q}=\max \{q\} .
\end{array}\right.
$$

Simulating the response of the wavy-ply sandwich with crushable core requires a correct representation of the tensile and shear failure of the foam. Consequently, the values of $\sigma_{\mathrm{C}}^{\mathrm{y}}, X_{\mathrm{T}}$ and $S$ provided in Table 5 were used to calibrate the two input parameters $k$ and $k_{\mathrm{T}}$ required by Abaqus, through the method derived below.

Following the definition of $p$ and $q$ in Equation A.1a, the three known points in the initial yield surface are:

$$
\left\{\begin{array}{llll}
\text { Uniaxial compressive failure: } & \sigma_{1}=-\sigma_{\mathrm{C}}^{\mathrm{y}} & \Longrightarrow & \left(p=\sigma_{\mathrm{C}}^{\mathrm{y}} / 3, q=\sigma_{\mathrm{C}}^{\mathrm{y}} \quad\right) \\
\text { Uniaxial tensile failure: } & \sigma_{1}=X_{\mathrm{T}} & \Longrightarrow \quad\left(p=X_{\mathrm{T}} / 3, q=X_{\mathrm{T}}\right) \\
\text { Shear failure: } & \tau_{12}=S \quad \Longrightarrow \quad(p=0 \quad, q=\sqrt{3} \cdot S) .
\end{array}\right.
$$

Replacing these points into Equation A.2 leads to

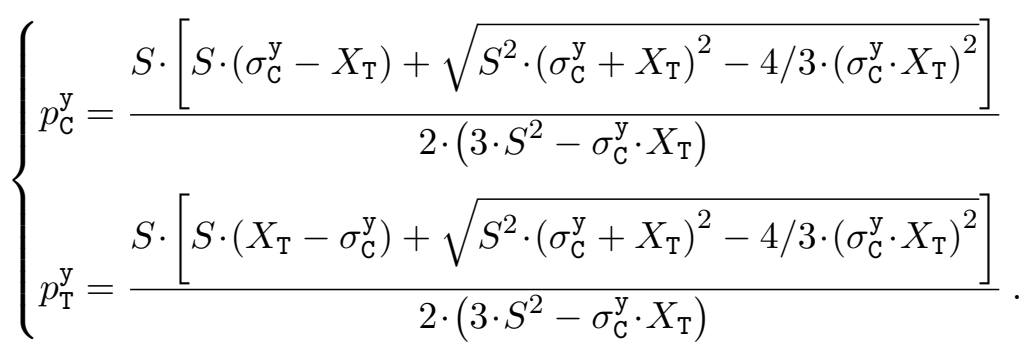

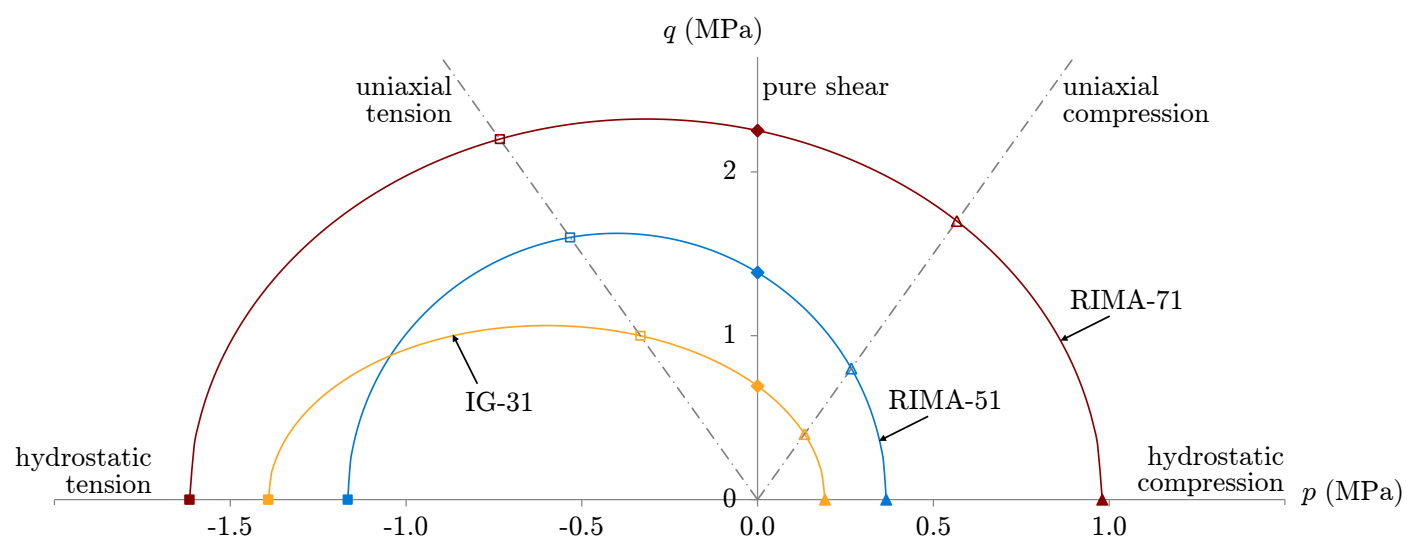

Figure A.1: Initial yield surfaces for the foams simulated. 
Finally, the corresponding values of $\sigma_{\mathrm{C}}^{\mathrm{y}}, p_{\mathrm{C}}^{\mathrm{y}}$ and $p_{\mathrm{T}}^{\mathrm{y}}$ can be replaced in Equation A.1b, generating the input values for $k$ and $k_{\mathrm{T}}$ as shown in Table 7 . The resulting initial yield for the three foam materials considered are presented in Figure A.1.

\section{Appendix A.2. Progressive strain hardening}

Abaqus's model for crushable foam with volumetric hardening assumes that the yield point for hydrostatic tension is independent of strain, and uncouples loading along principal material directions. The engineering strain-hardening behaviour of the crushable foams was modelled using a third order polynomial law,

$$
\begin{aligned}
& \sigma_{\mathrm{C}}^{\text {eng }}=\sigma_{\mathrm{C}}^{\mathrm{y}}+a_{3} \cdot\left(\varepsilon_{\mathrm{C}}-\varepsilon_{\mathrm{C}}^{\mathrm{h}}\right)^{3}+a_{2} \cdot\left(\varepsilon_{\mathrm{C}}-\varepsilon_{\mathrm{C}}^{\mathrm{h}}\right)^{2}+a_{1} \cdot\left(\varepsilon_{\mathrm{C}}-\varepsilon_{\mathrm{C}}^{\mathrm{h}}\right) \\
& \text { fitted under the conditions }\left\{\begin{array}{l}
\frac{\mathrm{d} \sigma_{\mathrm{C}}}{\mathrm{d} \varepsilon_{\mathrm{C}}}\left(\varepsilon_{\mathrm{C}}=\varepsilon_{\mathrm{C}}^{\mathrm{h}}\right)=0 \Longrightarrow a_{1}=0 \\
\frac{\mathrm{d} \sigma_{\mathrm{C}}}{\mathrm{d} \varepsilon_{\mathrm{C}}}\left(\varepsilon_{\mathrm{C}}=1\right)=E \Longrightarrow a_{3}=\frac{E-2 \cdot a_{2} \cdot\left(\varepsilon_{\mathrm{C}}-\varepsilon_{\mathrm{C}}^{\mathrm{h}}\right)}{3 \cdot\left(\varepsilon_{\mathrm{C}}-\varepsilon_{\mathrm{C}}^{\mathrm{h}}\right)} .
\end{array}\right.
\end{aligned}
$$

The stress-strain response for the three foams considered is shown in Figure 5, and the corresponding parameters are presented in Table 7 . The input true compressive stresses $\left(\sigma_{\mathrm{C}}^{\text {true }}\right)$, compressive strains $\left(\varepsilon_{\mathrm{C}}^{\text {true }}\right)$ and plastic strains $\left(\varepsilon_{\mathrm{C}}^{\mathrm{p}}\right)$ were then calculated as:

$$
\sigma_{\mathrm{C}}^{\text {true }}=\sigma_{\mathrm{C}} \quad \text { and } \quad\left\{\begin{array}{c}
\varepsilon_{\mathrm{C}}^{\text {true }}=-\ln \left(1-\varepsilon_{\mathrm{C}}\right) \\
\varepsilon_{\mathrm{C}}^{\mathrm{p}}=\varepsilon_{\mathrm{C}}^{\text {true }}-\frac{\sigma_{\mathrm{C}}}{E} .
\end{array}\right.
$$

\section{Acknowledgements}

This work was funded under the EPSRC Programme Grant EP/I02946X/1 on High Performance Ductile Composite Technology, in collaboration with the University of Bristol. The authors thankfully acknowledge the contribution from N. Hallstein and H. Yasin from EVONIK INDUSTRIES AG, for providing the foam material and for their helpful advice.

\section{References}

[1] T.-W. Chou and K. Takahashi. Non-linear elastic behaviour of flexible fibre composites. Composites, 18(1):25-34, 1987.

[2] H. Khatam and M.-J. Pindera. Microstructural scale effects in the nonlinear elastic response of bio-inspired wavy multilayers undergoing finite deformation. Composites Part B: Engineering, 43(3):869-884, 2012. 
[3] T. Yokozeki, S.-I. Takeda, T. Ogasawara, and T. Ishikawa. Mechanical properties of corrugated composites for candidate materials of flexible wing structures. Composites Part A: Applied Science and Manufacturing, 37(10):1578-1586, 2006.

[4] J. J. Carruthers, A. P. Kettle, and A. M. Robinson. Energy absorption capability and crashworthiness of composite material structures: A review. Applied Mechanics Reviews, 51(10):635-649, 1998.

[5] G. Pitarresi, J. J. Carruthers, A. M. Robinson, G. Torre, J. M. Kenny, S. Ingleton, O. Velecelad, and M. S. Found. A comparative evaluation of crashworthy composite sandwich structures. Composite Structures, 78(1):34-44, 2007.

[6] R. A. W. Mines, C. M. Worrall, and A. G. Gibson. The static and impact behaviour of polymer composite sandwich beams. Composites, 25(2):95-110, 1994.

[7] T. S. Lim, C. S. Lee, and D. G. Lee. Failure modes of foam core sandwich beams under static and impact loads. Journal of Composite Materials, 38(18):1639-1662, 2004.

[8] C. Winkelmann, S. S. Kim, and V. L. Saponara. Design and development of hybrid composite bistable structures for energy absorption under quasi-static tensile loading. Composite Structures, 93(1):171-178, 2010.

[9] L. Arronche, I. Martínez, V. L. Saponara, and E. Ledesma. Finite element modeling and experimental characterization of enhanced hybrid composite structures for improved crashworthiness. Journal of Applied Mechanics, 80(5):1-9, 2013.

[10] J. Reany and J. L. Grenestedt. Corrugated skin in a foam core sandwich panel. Composite Structures, 89(3):345-355, 2009.

[11] C. Quon, L. Cheng, Y. Li, and W. Yu. Confinement of concrete with hybrid FRP bistable structures. Cement and Concrete Composites, 37:222-231, 2013.

[12] Imperial Innovations Limited. Structural composite material. UK Patent: application 1405824.2, 1 April 2014.

[13] Hexcel Corporation. HexPly M21 Product Data — Publication FTA 002c, March 2007.

[14] Z. Jehangir. Experimental investigation of the translaminar ply fracture toughness of advanced composites. MEng Project Report, Imperial College London, UK, 2011.

[15] M. Ilyas, F. Lachaud, C. Espinosa, and M. Salaün. Dynamic delamination of aeronautic structural composites by using cohesive finite elements. In 17th International Conference on Composite Materials, Edinburgh, Scotland, 27-31 July 2009. 
[16] M. J. Laffan, S. T. Pinho, P. Robinson, and A. J. McMillan. Translaminar fracture toughness testing of composites: A review. Polymer Testing, 31(3):481-489, 2012.

[17] EVONIK INDUSTRIES AG. Heat Treatment of ROHACELL. www.rohacell. com/sites/dc/Downloadcenter/Evonik/Product/ROHACELL/product-information/ ROHACELL\%20Heat\%20Treatment.pdf, January 2011.

[18] EVONIK INDUSTRIES AG. ROHACELL IG/IG-F - Product Information. Www.rohacell.com/sites/dc/Downloadcenter/Evonik/Product/ROHACELL/ product-information/ROHACELL\%20IG_IG-F\%20Product\%20Information.pdf, March 2013.

[19] E. Saenz, A. Roth, F. Rosselli, X. Liu, and R. Thomson. Mode I fracture toughness of PMI sandwich core materials. In 8th International Conference on Sandwich Structures, Porto, Portugal, 6-8 July 2008.

[20] Dassault Systemes Simulia Corp. Abaqus 6.11 Analysis User's Manual, 2011.

[21] Q. M. Li, R. A. W. Mines, and R. S. Birch. The crush behaviour of ROHACELL-51 WF structural foam. International Journal of Solids and Structures, 37(43):6321-6341, 2000.

[22] S. Arezoo, V. L. Tagarielli, N. Petrinic, and J. M. Reed. The mechanical response of ROHACELL foams at different length scales. Journal of Materials Science, 46(21):6863$6870,2011$.

[23] R. Juntikka and S. Hallstrom. Weight-balanced drop test method for characterization of dynamic propertiesof cellular materials. International Journal of Impact Engineering, 30(5):541-554, 2004.

[24] EVONIK INDUSTRIES AG. ROHACELL WF - Product Information. www.rohacell.com/sites/dc/Downloadcenter/Evonik/Product/ROHACELL/ product-information/ROHACELL\%20WF\%20Product\%20Information.pdf, January 2011.

[25] EVONIK INDUSTRIES AG. ROHACELL RIMA — Product Information. www.rohacell.com/sites/dc/Downloadcenter/Evonik/Product/ROHACELL/ product-information/ROHACELL\%20RIMA\%20Product\%20Information.pdf, last accessed in June 2013. 